\title{
Neurodegenerative diseases: a hotbed for splicing defects and the potential therapies
}

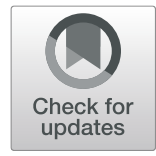

\author{
Dunhui $\mathrm{Li}^{1,2 \dagger}{ }^{1}$, Craig Stewart McIntosh ${ }^{1,2 \dagger}{ }^{2}$, Frank Louis Mastaglia ${ }^{1,2}$, Steve Donald Wilton ${ }^{1,2}$ and \\ May Thandar Aung-Htut ${ }^{1,2^{*}}$ (D)
}

\begin{abstract}
Precursor messenger RNA (pre-mRNA) splicing is a fundamental step in eukaryotic gene expression that systematically removes non-coding regions (introns) and ligates coding regions (exons) into a continuous message (mature mRNA). This process is highly regulated and can be highly flexible through a process known as alternative splicing, which allows for several transcripts to arise from a single gene, thereby greatly increasing genetic plasticity and the diversity of proteome. Alternative splicing is particularly prevalent in neuronal cells, where the splicing patterns are continuously changing to maintain cellular homeostasis and promote neurogenesis, migration and synaptic function. The continuous changes in splicing patterns and a high demand on many cis- and trans-splicing factors contribute to the susceptibility of neuronal tissues to splicing defects. The resultant neurodegenerative diseases are a large group of disorders defined by a gradual loss of neurons and a progressive impairment in neuronal function. Several of the most common neurodegenerative diseases involve some form of splicing defect(s), such as Alzheimer's disease, Parkinson's disease and spinal muscular atrophy. Our growing understanding of RNA splicing has led to the explosion of research in the field of splice-switching antisense oligonucleotide therapeutics. Here we review our current understanding of the effects alternative splicing has on neuronal differentiation, neuronal migration, synaptic maturation and regulation, as well as the impact on neurodegenerative diseases. We will also review the current landscape of splice-switching antisense oligonucleotides as a therapeutic strategy for a number of common neurodegenerative disorders.
\end{abstract}

Keywords: Neurodegenerative diseases, Parkinson's disease, Alzheimer's disease, Alternative splicing, Splicing defects, Antisense oligonucleotides, Splice-switching, Disease-modifying treatment

\section{Introduction}

Neurodegenerative diseases are a large and heterogenous class of disorders that are categorised primarily by the loss of function or structural integrity of neurons and associated cell types in the nervous system. Typically, these diseases are progressive in nature and often, but not always, manifest in adult life, with the vast majority of

\footnotetext{
* Correspondence: m.aung-htut@murdoch.edu.au

${ }^{+}$Dunhui Li and Craig Stewart McIntosh contributed equally to this work.

${ }^{1}$ Centre for Molecular Medicine and Innovative Therapeutics, Health Futures Institute, Murdoch University, Perth, Western Australia, Australia

${ }^{2}$ Perron Institute for Neurological and Translational Science, Centre for Neuromuscular and Neurological Disorders, The University of Western Australia, Perth, Western Australia, Australia
}

diseases having no cure or effective treatment strategy [1-5]. The progressive loss of functional neurons underlies the cognitive and motor impairments seen in neurodegenerative diseases [6]. The most common pathological feature observed in neurodegenerative diseases is the accumulation of insoluble misfolded protein aggregates [7-10]. These aggregates take various constitutive forms, depending on the specific disease type and/ or genetic cause. Most cases of neurodegeneration are sporadic, but common genetic forms can be caused by mutations in the gene that lead to conformational changes of the encoded protein, making the protein highly likely to misfold and aggregate [3]. Although

(c) The Author(s). 2021, corrected publication 2021. Open Access This article is licensed under a Creative Commons Attribution 4.0 International License, which permits use, sharing, adaptation, distribution and reproduction in any medium or format, as long as you give appropriate credit to the original author(s) and the source, provide a link to the Creative Commons licence, and indicate if changes were made. The images or other third party material in this article are included in the article's Creative Commons licence, unless indicated otherwise in a credit line to the material. If material is not included in the article's Creative Commons licence and your intended use is not permitted by statutory regulation or exceeds the permitted use, you will need to obtain permission directly from the copyright holder. To view a copy of this licence, visit http://creativecommons.org/ licenses/by/4.0/. The Creative Commons Public Domain Dedication waiver (http://creativecommons.org/publicdomain/zero/1. 0/) applies to the data made available in this article, unless otherwise stated in a credit line to the data. 
neurodegenerative diseases are mainly sporadic, there are clear underlying genetic causes for neurodegenerative diseases, and errors that affect normal splicing are relatively common [4].

At the completion of the Human Genome Project, it was determined that there are approximately 23,000 protein-coding genes in the human genome. Interestingly, the number of genes has no relation to the complexity of an organism, as the common wheat plant carries roughly 95,000 protein-coding genes, while the loblolly pine tree contains a genome ( 23 billion bases) that is roughly 10 times that of the human ( 2.3 billion bases) $[11,12]$. It has been established that alternative splicing is responsible for the great discrepancy among the $\sim 23,000$ protein-coding genes in the human genome, which gives rise to $\sim 200,000$ different gene transcripts and around 2 million different proteins that they encode [13]. Alternative splicing is a process whereby multiple different mRNA isoforms arise from a single proteincoding gene, achieved by the exclusion or inclusion of single or multiple exons, or by the use of alternative splicing sites to give rise to partial exons or the retention of an intronic sequence, in essence blurring the strict definition of exons and introns unless temporal, spatial, environmental or tissue-specific caveats are taken into consideration [14]. However, to fully understand the mechanisms that lead to alternative splicing and thus potential disease-causing splicing mutations, one must first understand the process of precursor messenger RNA (pre-mRNA) splicing as a whole.

\section{Pre-mRNA splicing}

Pre-mRNA splicing is an integral step in "split" gene expression, which occurs in all higher eukaryotes and some lower eukaryotes. All pre-mRNA transcripts contain defined sequences destined for inclusion in the mature mRNA isoform (exons) and are separated by sequences that are excluded from the mature mRNA (introns) [15]. During mRNA maturation, the introns are removed whilst the exons are assembled and precisely ligated together to form a continuous mature mRNA transcript, ready for export and potential protein translation or regulatory function. The splicing processing requires a highly coordinated arrangement of numerous splicing RNA and protein factors that act together with a range of splicing motifs to produce a large multi-protein complex termed the spliceosome to coordinate these molecular gymnastics (Fig. 1) [20]. Considered most simplistically, this process consists of two sequential transesterification reactions that ligate adjacent exons. However, this process is far from simple and involves hundreds of interacting proteins and small nuclear RNAs (snRNAs) and a number of small nuclear ribonucleoproteins (snRNPs). In the absence of mutations, the process of splicing is highly ordered and precise, involving several multi-component splicing factors with the addition of the above mentioned snRNPs (Fig. 1). Pre-mRNA splicing is so finely balanced and intricately tuned that errors in cis- and/or trans-splicing motifs/factors can commonly occur and are thought to account for up to a third of all human diseases [21], in particular neurodegenerative diseases.

\section{Alternative Splicing}

As previously mentioned, alternative splicing is critical not only for the diversification in specific species, but also for tissue specificity within organisms. Furthermore, the differences in splicing and ultimately mRNA sequence may have an effect on mRNA stability, localisation and translation [22], resulting in various protein isoforms with distinct and sometimes opposing biological functions. The common mechanisms of alternative splicing are shown in Fig. 2. A perfect example of this is the alternative splicing within the receptor for advanced glycosylation end products $(R A G E)$ gene. RAGE is a multiligand receptor of the immunoglobulin superfamily that plays an integral role in inflammation and innate immune response. The alternative splicing of $R A G E$ leads to three main isoforms with distinct biological functions, the full-length membrane RAGE (mRAGE), soluble RAGE (sRAGE) and N-truncated RAGE (NtRAGE) [23-25].

There are numerous cis-acting elements that regulate splicing and it is these elements that may cause subtle differences in recognition of the exon by the spliceosome, giving rise to alternatively spliced transcripts [14]. Alternative exons or sequences share similar 3' and 5' splice sites; however, they typically have a weaker binding affinity to the spliceosome than consensus exons, resulting in reduced recognition [26]. Next to splice site recognition, splicing factors play a major role in alternative exon recognition. Serine and arginine-rich (SR) proteins typically enhance the recognition of alternative exons, while heterogeneous nuclear ribonucleoproteins (hnRNPs) conversely aid in exclusion of the exon from the mature mRNA transcript. However, as in many cases in biology, there are clear exceptions to these generalisations $[27,28]$, where two SR proteins, SF2/ASF and hTra2-beta, have been shown to cause skipping of several ceramide-regulated exons from the mature mRNA isoforms [27].

Alternative splicing is evidently an integral component of the neuronal gene expression network that regulates cell differentiation, tissue homeostasis and organ development [22]. A key feature is the tissue-specific alternative splicing, whereby specific mRNA isoforms from the 


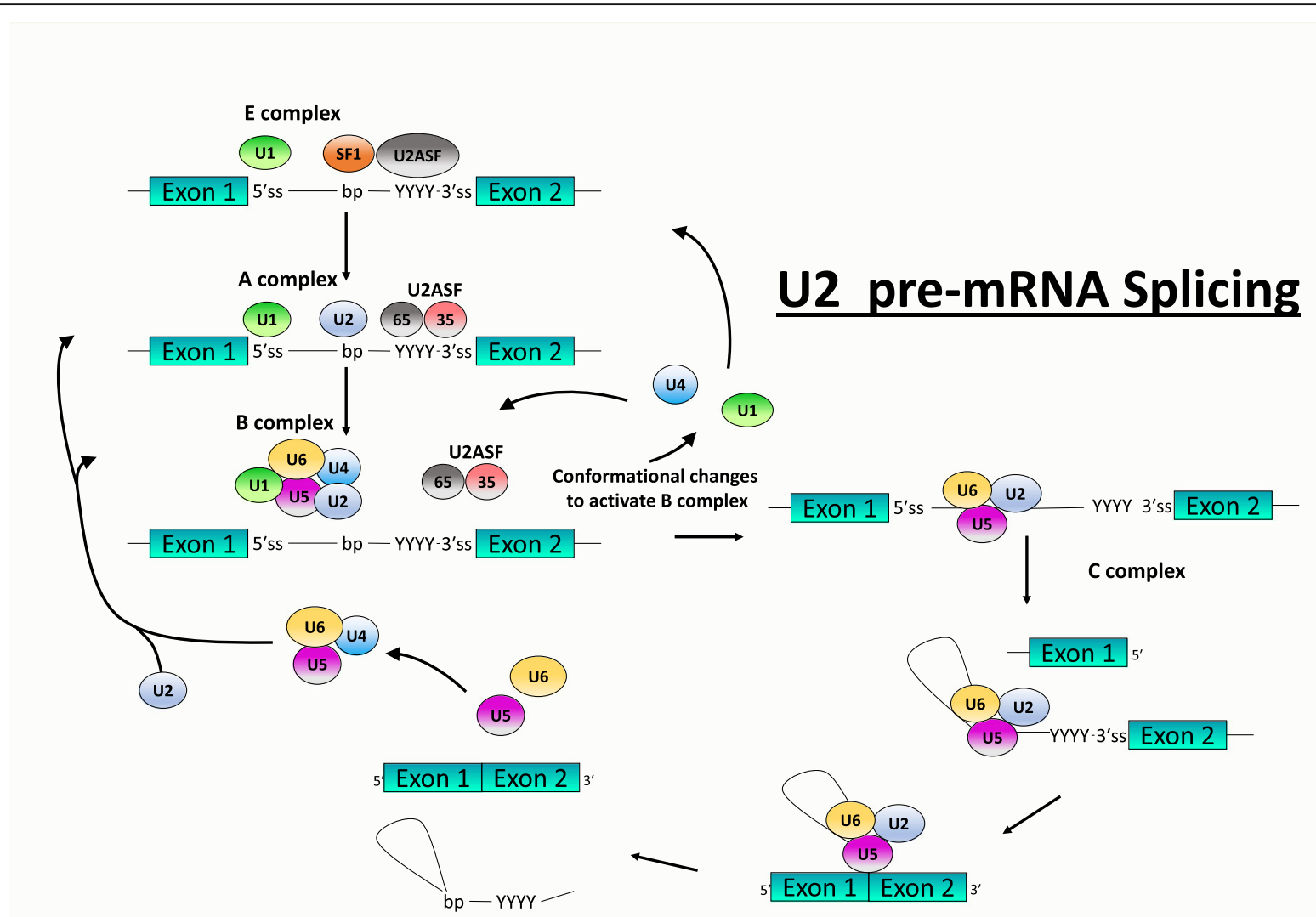

Fig. 1 Schematic of the process of pre-mRNA splicing and major spliceosome assembly. Initial assembly into Complex E involves binding of the U1 snRNP (U1) to the 5'splice site (ss), while non-snRNP splicing factor 1 (SF1) and U2AF bind to the branchpoint sequence and polypyrimidine tract, respectively [16]. Subsequently, U2 snRNP is recruited by SF1 and U2AF, replaces SF1 to bind to the branchpoint, and initiates the formation of Complex A. The recruitment of U2 then facilitates enlistment of the U4/U6-U5 tri-snRNP that is pre-assembled from the U4/U6 and U5 snRNPs, thus forming the pre-catalytic Complex B. Next, destabilisation of U4 and U1 leads to the dissociation of U4, while U6 replaces U1 at the 5'ss and gives rise to the activated spliceosome. This catalytically activated Complex B initiates the first step in splicing, giving rise to Complex $C$ that then cleaves the 5'ss, releasing the first exon to fold and the 5'ss can now join to the branchpoint, forming a lariat within the intron. Following the lariat formation is the second step in splicing; cleavage of the intron at the 3'ss, release of the lariat and the ligation of the two bordering exons. Upon completion of the final step, the spliceosome dissociates so that the snRNPs may be recycled and splicing of a subsequent intron occurs. This is repeated until all the introns from the mRNA are removed, thus giving rise to the formation of the mature mRNA transcript [17, 18]. Following intron excision and ligation of the exons, the $U$ snRNPs are recycled. 5'ss, 3'ss, bp and polypyrimidine tracts are shown in the line representing the intron. Exons are shown as magenta boxes. Adapted from Pitout (2019) [19].

same gene are selectively expressed and translated in different tissues or cell types or during specific stages of development or metabolic conditions. However, with a high degree of diversity and complexity, there is an increased potential for splicing errors, and in fact, errors in alternative splicing and in splicing in general are known to play many roles in diseases [15, 29-31].

\section{Tissue-specific splicing in the brain}

Alternative splicing is a fundamental aspect during the complex life cycle of a neuron, which occurs constantly throughout early neuronal differentiation to synapse formation, supporting cell plasticity and signalling, and is even critical for programmed cell death [32-35]. This extraordinarily complex and coordinated phenomenon creates a plethora of splice isoforms across various neuronal cell-types during development and adaptation [36, 37]. The nervous system is a well-established hotbed for alternative splicing of pre-mRNAs, which has been clearly shown to be a central mechanism underlying many neuronal functions [38-42]. Additionally, numerous splice sites seem to be evolutionarily conserved, which is consistent with a view that alternative splicing plays a central role in encoding properties essential for neuronal functions [43-46]. In fact, alternative splicing could be considered the norm in neuronal gene expression, rather than the exception, with the fact that between $15 \%-50 \%$ of human genetic diseases arise from mutations affecting the alternative splicing processes [47]. 


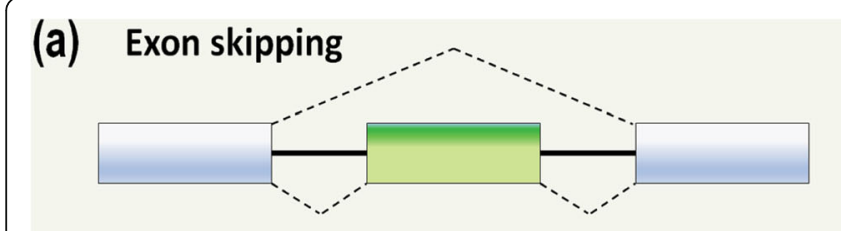

(b) Intron retention

(c) Alternative 5'ss selection

(d) Alternative 3'ss selection (e) Alternative poly(A) sites
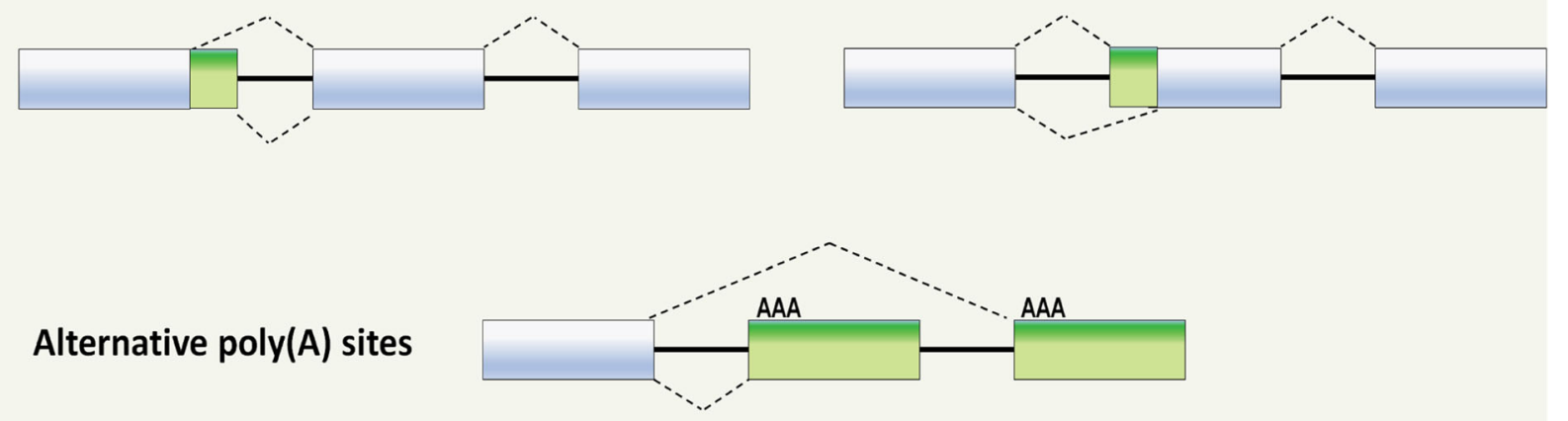

\section{(e)}

\section{(f) Mutually exclusive exons}

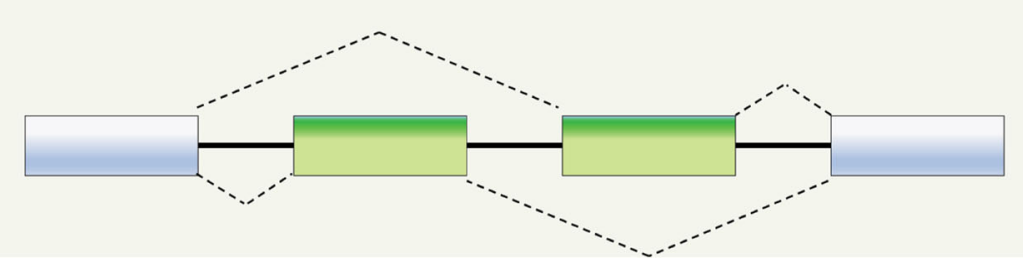

Fig. 2 Schematic of the most common forms of alternative splicing. a Exon skipping. b Intron retention. c Alternative 5' splice site (ss) selection. d Alternative $3^{\prime}$ ss selection. e Alternative polyadenylation (polyA) sites. f Mutually exclusive exons. Light blue boxes denote segments included in the final message, while green boxes denote segments excluded in the mature mRNA transcript. Dotted lines show the splicing pattern. Note: mechanisms are not mutually exclusive, and combinations can often occur.

\section{Alternative splicing and neuronal differentiation}

The brain is an extremely complex organ with numerous cell types working in coordination to achieve homeostasis. In order to produce this intricate mesh of cell types there is a requirement for organised and coordinated activation and inactivation of transcriptional regulators. In addition, there is delicate and coordinated expression of various trans-acting splicing factors that bind cis-elements in pre-mRNAs to either promote or hinder recruitment of the spliceosome at intron/exon boundaries (Fig. 1) [26, 48]. Splicing factors bind to single or clusters of RNA motifs located in introns and exons, to either enhance or inhibit target exon inclusion as required [49]. In a neurological setting, specific RNA-binding proteins, particularly polypyrimidine tract binding protein 1 (PTBP1) and SR-rich (serine/arginine) repetitive matrix protein 4 (SRRM4), play an essential role in cellular differentiation [33, 50-52]. It is now known that the alternative splicing patterns of PTBP1 and SRRM4 transcripts undergo drastic changes over the course of early neurogenesis [53].
PTBP1

Members of the PTB family share a high degree of homology and function but nevertheless exhibit distinct celltype expression patterns. For example, the full-length PTBP1 is largely absent in mature tissues such as neurons and muscles, while in tissues such as neuronal progenitors and neuronal stem cells, PTBP1 is highly expressed [54]. The expression of PTBP1 is known to decrease sharply upon mitotic exit (or maturation) through mRNA downregulation by the neuron-specific microRNA, miR-124 [55, 56]. Mechanistically, miR-124 has been shown to target PTBP1 mRNA directly, and this downregulation of PTBP1 globally represses nonneuronal alternative pre-mRNA splicing [55]. Among the binding targets of PTBP1 is a key cassette exon located within the pre-mRNA of PTB family member, PTBP2 [57].

$P T B P 1$ is highly expressed in the early stages of neurogenesis, which in turn promotes PTBP1 binding to $P T B P 2$, subsequently causing the cassette exon to be skipped, thereby subjecting PTBP2 to nonsense- 
mediated decay [55]. However, during the late stage of neuronal differentiation, high levels of miR-124 repress PTBP1 expression (thus reducing PTBP1 binding to $P T B P 2)$, leading to the inclusion of the cassette exon located in $P T B P 2$ and thus an increase in the full-length PTBP2 transcript. This subtle difference in PTBP1 expression induces the transition of alternative splicing from a non-neuronal to a neuronal-specific pattern [55]. Another critical gene that interacts with PTBP1 for neuronal differentiation is SRRM4.

\section{SRRM4}

SRRM4 is similar in structure to the serine/arginine (SR)-rich splicing factor family, and is a crucial factor for alternative splicing patterns found exclusively in neuronal cells [58]. Although SRRM4 lacks typical RNAbinding domains, it commonly binds to UGC-rich motifs that are located between the 3'-splice site and the polypyrimidine tract [22]. The most common motifs targeted by SRRM4 are typical PTBP1-binding targets, leading to the notion that SRRM4 antagonises PTBP1. SRRM4 participates in neurogenesis through its role in neurite outgrowth [59]. In 2016, Nakayama and colleagues demonstrated that SRRM4 regulates splicing of protrudin gene (Zfyve27) transcripts in mouse Neuro2A cells. They showed that SRRM4 promotes the inclusion of a micro-exon (encoding only seven amino acids) within the mature transcript of protrudin, through the UGCrich motif that is located immediately upstream of the micro-exon [59]. The resulting protein, termed protrudin-L, was shown to promote neurite outgrowth during neurogenesis. In fact, SRRM4 has broad effects on the selection of neuronal specific micro-exons [58]. Several SRRM4-regulated micro-exons have demonstrated high levels of inclusion during neuronal maturation, which is directly correlated to the high levels of SRRM4 [58, 60, 61]. Following neuronal differentiation, maturation and synaptogenesis occur over a sustained period of time.

\section{Alternative splicing and neuronal migration}

Following differentiation, neuronal cells need to migrate to their respective brain regions, and similar to differentiation, this process relies heavily on alternative splicing, particular the alternative splicing factor neurooncological ventral antigen 2 (NOVA2).

NOVA2 protein has been shown to regulate transcripts that encode synapse-related molecules in the postnatal brain as well as playing a critical role in neuronal cell migration. There are two NOVA paralogues, NOVA1 and NOVA2; they both contain KH-type RNAbinding domains. NOVA1 is primarily expressed in the ventral spinal cord and hindbrain, while NOVA2 is expressed in the dorsal spinal cord and forebrain [62].
Their critical involvement in neuronal migration and differentiation is evident with severe phenotypes observed in knockout models [62]. The NOVA2 gene is critical for proper cortical lamination. In Nova 2 knockout mice, neuronal migration defects occurred in both the cerebral cortex and the cerebellum [63], while the progenitor cell morphology was mostly unaffected. This suggests a defect in neuronal migration rather than complications arising from incorrect tissue subtype specification [63]. The defective migration of the upper layers of mouse neurons is widely attributed to the mis-splicing of disabled 1 (Dab1) [64].

Dab1 is a protein involved in the Reelin signalling pathway, a pathway that is responsible for the positioning of neurons, as well as the growth, maturation and synaptic activity of neuronal cells $[65,66]$. In the presence of NOVA2, two exons (exons $7 \mathrm{~b}$ and 7c) found within the Dab1 transcript are excluded from the mature mRNA, resulting in an unstable Dab1 isoform that is tagged for ubiquitination upon activation of the Reelin pathway [63, 67]. Conversely, in the absence of NOVA2, these exons are included and provide stability to the specific Dab1 isoform [63, 67]. The role of NOVA2 is not limited to neuronal migration, but also in synaptic maturation and plasticity. This suggests that NOVA proteins are critical to brain-specific splicing through multiple stages of development.

\section{Alternative splicing and synaptic maturation and regulation}

Once the cell fate and the location are determined, a high degree of alternative splicing is still needed for neuronal cells to undergo maturation and function properly. Genes such as PTBP1, PTBP2, SRRM4, NOVA2, and RNA binding Fox-1 Homolog $1 / 2$ (RBFOX1/2) play a critical role in the maturation and on-going functionality $[14,22,44,68]$.

\section{Synaptic maturation}

Compared to most other cell types, neurons undergo an unusually long maturation period. Once signalling for differentiation and migration comes to an end, changes in splicing patterns lead to the development from initial neurites to defined axons and dendrites, which finally assemble to form active synaptic connections and signalling $[57,69]$. One of the initial changes observed is a dramatic reduction in the level of splicing factor PTBP1, while the level of the related PTBP2 protein increases. The shift in expression denotes the end of cell differentiation and the commencement of maturation. Homozygous knockout of Ptbp2 in mice leads to the degeneration of cortical neurons during a developmental period which otherwise should see the cortex expand and develop mature working synapses [69]. Although 
PTBP2 depletion leads to degeneration, it does not hinder neuronal differentiation, suggesting that PTBP2 is not necessary during early neurogenesis [69]. Mechanistically, the depletion of PTBP2 can cause mis-regulations of several splicing patterns in the mouse brain, with the PTBP2-targeted exons/transcripts known to encode proteins that affect neurite growth and synaptic transmission and assembly [69]. Apart from PTBP2, SRRM4 has also been shown to be an integral factor involved in synaptogenesis.

Several targets of SRRM4 overlap with those of PTBP2, suggesting a similar role of them in synaptic maturation. In fact, Srrm $4^{\Delta 7-8}$ mice exhibit a similar phenotype to the previously described Ptbp 2 knockout model [58]. The Srrm $4^{\Delta 7-8}$ mice carry a heterozygous conditional deletion of exon 7 and exon 8 throughout the animal and in the germline, resulting in widespread loss of the functional full-length protein [58]. This loss of functional Srrm4 leads to aberrant splicing in the brain in several gene transcripts implicated in vesicle trafficking. Homozygous Srrm $4^{47-8 / \Delta 7-8}$ mice display a severe phenotype with $85 \%$ mortality within the first few weeks of life. Although the mice show no obvious gross morphological phenotype, they soon develop respiratory complications and cyanosis [58]. Interestingly, the surviving mice did not show a significant difference in life span when compared to the wild-type littermates but displayed pronounced neurobiological phenotypes. These findings suggest that Srrm4 plays a role in developmental neurogenesis and in normal synaptic functioning.

\section{Synaptic regulation}

Once synapses are fully formed, the regulation and function of each synapse still requires high levels of alternatively spliced genes. At the forefront of this are the splicing factors RBFOX1 and RBFOX2 [33, 70]. It has been shown that mutations in RBFOX1 lead to various epileptic phenotypes, indicating its role in synaptic excitability. Transcriptome analysis of homozygous $R b f o x 1^{-1-}$ mouse brains showed numerous splicing changes in target transcripts of Rbfox1, although no significant change in transcript abundance was observed [70]. These changes in splicing pattern were shown to affect proteins that mediate synaptic excitation and transmission. The phenotype of the mice seemed to confirm this finding as they had spontaneous, infrequent seizures when compared to wild-type mice [70]. Complementary to this, Jacko et al. (2018) generated triple Rbfox1/2/3 knockout (tKO) spinal neurons to examine and characterise the complex network of alternatively spliced genes targeted by the Rbfox family [33]. The tKO neurons harboured several alternative splicing defects in genes encoding proteins responsible for the regulation of neuronal membranes and synaptic function [33]. In fact, tKO neurons appear to display immature electrophysiological activity, through diminished axon initial segments, a structure critical for action potential initiation [33]. The tKO neurons were shown to have more severe splicing changes when compared to murine brains in which individual Rbfox genes were knocked out, highlighting important roles of all three Rbfox genes in the regulation of alternative splicing in the brain [33, 70-72].

It is clear that the brain is a hotbed for alternative splicing, and although alternative splicing is invaluable, it does come with several potential drawbacks. Many neurodegenerative diseases have been linked to defects in splicing, including Parkinson's disease (PD), Alzheimer's disease (AD) and spinal muscular atrophy (SMA).

\section{Alternative splicing and splicing defects in neurodegenerative diseases \\ PD}

$\mathrm{PD}$ is a progressive neurodegenerative disorder whose aetiology is thought to involve an interaction between a wide range of environmental toxins and genetic risk factors. PD has a pathological hallmark of the presence of intraneuronal cytoplasmic inclusions, called Lewy bodies. The major component of Lewy bodies is alphasynuclein (SNCA), which is a $14 \mathrm{kDa}$ protein that regulates synaptic vesicle release and trafficking, membrane channel formation, and neurotransmitter release [73]. Mutations in SNCA, including missense mutations A53T and $\mathrm{A} 30 \mathrm{P}$ or overexpression (through duplication or triplication of the SNCA gene), cause SNCA misfolding and an increase in the relative expression of SNCA, thereby promoting SNCA oligomerization and aggregation. As SNCA aggregates, fibrils eventually impair many molecular pathways including autophagy, the ubiquitinproteasome protein degradation system, and mitochondrial homeostasis [74-76]. In addition, emerging evidence shows that different SNCA isoforms, generated from $S N C A$ alternative splicing, have different aggregation propensities and thus play an important role in $\mathrm{PD}$ pathophysiology.

Multiple minor SNCA transcripts have been reported, and although not prevalent, these transcripts are primarily alternatively spliced at the 5'-untranslated region (UTR) or 3'-UTR. For the 5'-UTR, over 10 different initial exons have been reported, with varying lengths [77]. With respect to the 3'-UTR, brain-specific alternative selection of polyadenylation sites generates at least three different SNCA transcripts with varying lengths of 3'UTR. However, the differences in the length of 5 -UTR and 3'-UTR have been suggested to have no impact on the overall total protein production or the coding sequence [78].

There are five main $S N C A$ transcripts resulting from alternative splicing of $S N C A$ exon 3, exon 5, or both 
(Fig. 3a). The full-length $S N C A$ (SNCA140) is the most abundant transcript, making up $96.7 \%-98.1 \%$ of the total SNCA mRNA transcripts [79]. The expression levels of these alternatively spliced isoforms are very low in healthy populations, but vary in patients with $\mathrm{PD}$, diffuse Lewy body dementia (DLBD) and MSA [80]. The SNCA112 transcript arises from the removal of exon 5, resulting in deletion of 28 amino acids at the C-terminal of the SNCA protein. The loss of three glutamic acids and an aspartic acid increases the net charge of SNCA, thus making SNCA112 more prone to aggregation compared to the full-length isoform. In addition, splicing out exon 5 results in the loss of amino acid S129, which is the major phosphorylation site of SNCA and is involved in SNCA clearance, aggregation and toxicity [81]. The loss of S129 has been suggested as the determinant factor for the higher aggregation properties of SNCA112 compared to SNCA140.

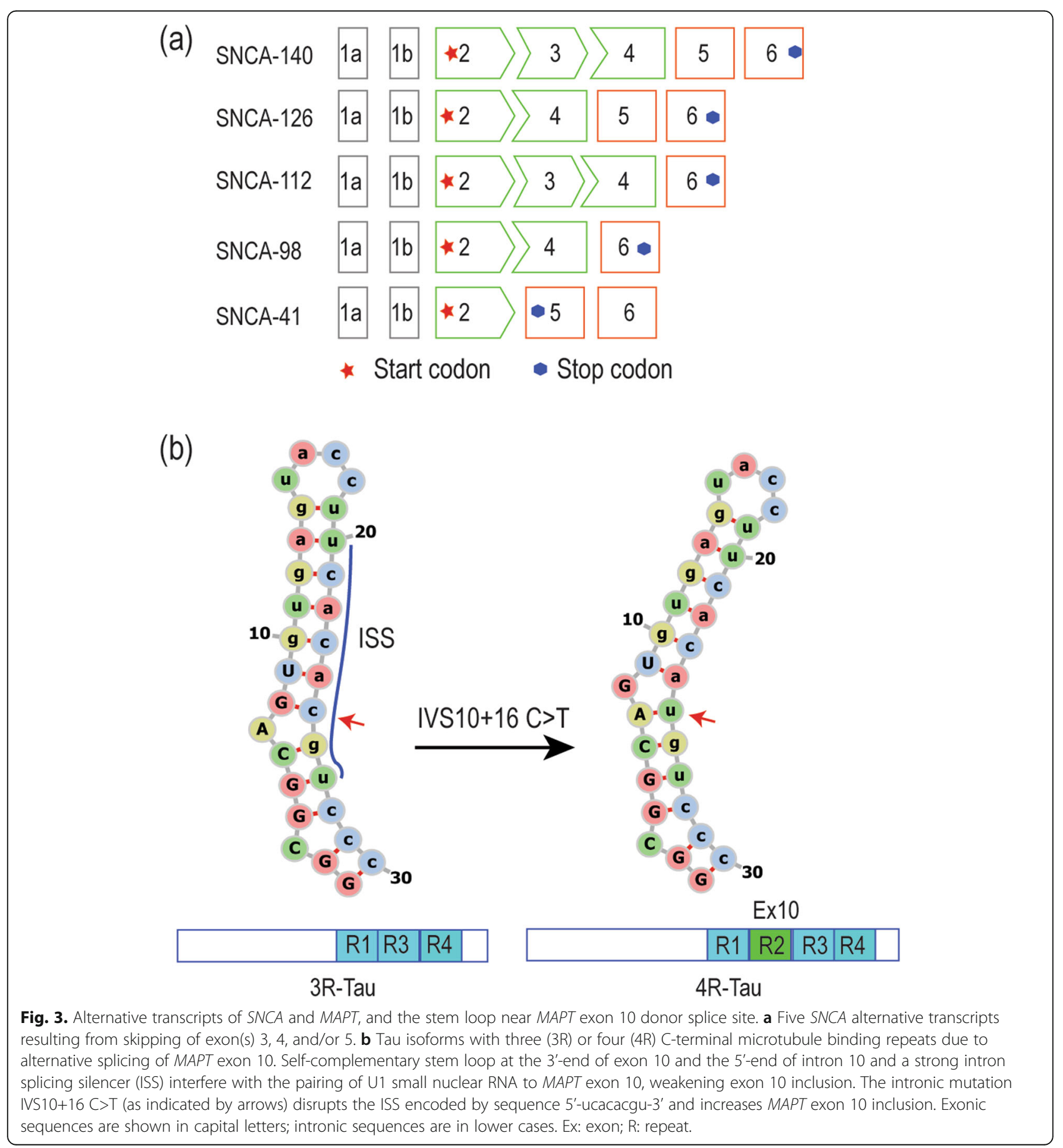


In contrast, the SNCA126 transcript that lacks exon 3 encodes a protein that shows low aggregation rates due to the loss of the highly amyloidogenic non-amyloid component region that contributes to SNCA oligomerization and aggregation. Since the C-terminal is unaffected in the SNCA126 isoform, the net charge of this isoform is even lower than SNCA140, thus SNCA126 is less likely to aggregate compared to the SNCA112 and SNCA140 isoforms. Clinical observations have demonstrated that SNCA126 is diminished in the frontal cortex of DLBD patients at synucleopathogy stages 5 and 6 [82]. However, PD patients at stages 3 and 4 show high levels of SNCA126, suggesting that SNCA126 may have some protective potential against the latter stages of disease. The SNCA41 transcript is a newly identified $S N C A$ alternative transcript expressed in PD brains [83]. The skipping of exons 3 and 4 generates a 238-bp transcript with a premature termination codon, which is translated into a short SNCA isoform of 41 amino acids. SNCA41 neither aggregates nor affects the fibrillation of full-length SNCA and is not deleterious to dopaminergic cells in vitro. However, PC12 cells pre-treated with recombinant SNCA41 showed increased dopamine uptake [83]. Since different SNCA isoforms have various pathophysiological functions, understanding the underlying mechanisms of the differential expression of these isoforms could provide insights into the development of novel therapeutic strategies.

Single nucleotide polymorphisms (SNPs) are natural genetic variants and can have neutral, functional or catastrophic biological effects [84]. The role of SNPs in PD pathogenesis is unequivocal, with several SNPs in the 3'-UTR being shown to alter the SNCA enhancer activity and lead to overexpression of $S N C A$ $[85,86]$. SNPs are also suggested to affect the expression of different SNCA isoforms. For example, SNP in intron 4 (rs2736990) and SNPs in 3'-UTR (rs356165 and rs356219) are associated with an increase in SNCA112 expression [87, 88]. As potential cis-acting splicing motifs are found around the sequences surrounding the SNPs, those SNPs are suggested to disrupt the splicing context and redirect normal SNCA splicing [89]. As SNCA structural variants, polymorphic microsatellites have been found to contribute to synucleinopathies through regulating SNCA gene expression and splicing [90]. The splicing efficiency of SNCA exon 3 is associated with one of three poly $(\mathrm{T}) n$ variants in $S N C A$ intron 2: the $5 \mathrm{~T}$ allele, 7T-allele, and $12 \mathrm{~T}$ allele [91]. Higher expression levels of SNCA126 are correlated with longer polyT stretch in the normal brain [77].

Alternative splicing events that affect cellular functions of proteins have also been found in other genes related with $\mathrm{PD}$, and aberrant splicing in these genes is suggested to contribute to the PD pathogenesis. Mutations in leucine-rich repeat kinase 2 (LRRK2) are the most common cause for the sporadic and late-onset familial PD [92]. LRRK2 functions are mainly affected by missense mutations spreading across the gene; however, several pathogenic mutations have been reported to affect the LRRK2 splicing [93]. Homozygous or compound heterozygous mutations in PARK2 account for $50 \%$ of autosomal recessive juvenile Parkinsonism and $15 \%$ of sporadic PD cases with onset before 45 years of age. The structural variations of $P A R K 2$ alternatively spliced transcripts are implicated in the mechanisms of juvenile Parkinsonism. PARK2 transcripts without exons 3-5 or exons 2-7 have been detected to be increased in $\mathrm{PD}$, and an alternatively spliced variant of parkin that lacks exon 4, which leads to null enzymatic activity, is upregulated in sporadic PD [94].

AD

$\mathrm{AD}$ is the most common neurodegenerative disease, characterised by progressive impairment in cognitive function and behaviour. Environmental exposure, aging and gene mutations are suggested to play a synergistic role in the pathogenesis of AD. To date, more than 50 loci have been implicated in $\mathrm{AD}$, although the functions and underlying disease mechanisms for most of those genes are still undetermined. Several genes and pathways are implicated in $A D$, including the $A \beta$ cascade, tau, inflammation, and cholinergic and oxidative stress [95]. Some of the gene products can be found in the extracellular amyloid plaques and intra-neuronal neurofibrillary tangles in the brains of AD patients, which are hallmark histopathologies of AD.

Tau is encoded by the microtubule associated protein tau (MAPT) gene, which consists of 16 exons. Alternative splicing of exon 10 gives rise to two tau isoforms, $3 R$ tau (exon 10 exclusion) and 4R tau (exon 10 inclusion) [96]. Moreover, the disrupted ratio between the $3 R$ and $4 \mathrm{R}$ isoforms is involved in tauopathies and $\mathrm{AD}$ pathogenesis [97], as the $4 \mathrm{R}$ tau has been shown to have stronger activity in promoting microtubule assembly and lead to greater neurodegeneration than the $3 R$ tau [98]. Several features including the weak 5 ' and 3 ' splice sites in $M A P T$ exon 10, and the self-complementary stem loop at the 3'-end of exon 10 and the 5'-end of intron 10 can cause a relatively low level of exon 10 inclusion [99]. Mutations including IVS10+16 $\mathrm{C}>\mathrm{T}$ that disrupts the stem loop structure (Fig. 3b) increase the binding of U1 small nuclear RNA and enhance MAPT exon 10 splicing, leading to the predominance of $4 \mathrm{R}$ tau in familial AD patients [100].

Misprocessing and accumulation of the $A \beta$ protein, a proteolytic product of amyloid precursor protein encoded by the APP gene, is another hypothesis for AD pathogenesis [101]. There are two major isoforms of $A \beta$, 
$A \beta 40$ and $A \beta 42$, depending on the cleavage site of $\gamma$ secretase. $A \beta 42$ is prone to aggregate and is the major component of amyloid plaques [102]. There have been about 60 mutations reported for APP and most of the pathogenic mutations are clustered in exons 16 and 17 that encode the cleavage sites for $\beta$ - and $\gamma$-secretase [103]. APP is alternatively spliced into as many as 11 different mRNA transcripts. Alternative inclusion of exons 7 and/or 8 generates three major $A P P$ transcripts: APP770 that contains both exons 7 and 8; APP751 that lacks exon 8; and APP695 that lacks both exons 7 and 8 [104]. Although APP695 is the predominant isoform in neurons, the other two minor isoforms are also suggested to be involved in $\mathrm{AD}$, albeit to a lesser extent.

Presenilin-1, encoded by the PSEN1 gene, is one of the core components of the $\gamma$-secretase complex that is responsible for the cleavage of APP and the generation of amyloid peptides [105-107]. Although most PSEN1 mutations are reported as missense variations, several pathogenic mutations can affect the alternative splicing, especially those near recognised canonical splice sites [108]. For example, the $A>G$ mutation in the acceptor splice site of intron 8 causes the skipping of exon 9, resulting in decreased $A \beta 40$ production, increased $A \beta 42 / A \beta 40$ ratio and disrupted cellular functions [109].

Presenilin-2 is another component of $\gamma$-secretase and is encoded by PSEN2. PSEN2 has also been shown to harbour mutations affecting the alternative splicing. A one-base-pair deletion in PSEN2 (c.10732delA) causes the loss of the canonical exon 12 acceptor site, resulting in exon 12 skipping and ultimately causes a frame-shift and premature termination codon [110]. The deletion of GA (c.342_343delGA) in PSEN2 exon 5 [111] has been found to result in a partial intron 5 retention and create an alternatively spliced PSEN2 transcript lacking exon 6 [112]. Although there are limited studies on exon 6 deletion in PSEN2 transcript, this mutation has been implicated in the pathogenic mechanisms of sporadic AD, including increasing $\gamma$-secretase activity, repressing the unfolded protein response and regulating inflammatory responses to hypoxic stress [113, 114].

For the majority of sporadic $\mathrm{AD}$ patients, the presence of the $\varepsilon 4$ allele of apolipoprotein $\mathrm{E}(A P O E)$ is one of the primary genetic risk factors. $A P O E$ has three different allelic variants $\varepsilon 2, \varepsilon 3$ and $\varepsilon 4$, where the presence of $\varepsilon 2$ lowers the $\mathrm{AD}$ risk, while conversely the increased expression of $\varepsilon 4$ increases the $\mathrm{AD}$ risk [115]. Although the mechanism of how $A P O E$ modifies $\mathrm{AD}$ risk is not completely understood, an additional copy of $A P O E \& 4$ is more likely to promote $A \beta$ aggregation and is thought to increase the stability of $\mathrm{A} \beta$ oligomers when compared to $A P O E \varepsilon 2$ or APOE \&3 [52, 116-119].

\section{Amyotrophic lateral sclerosis (ALS) and frontotemporal dementia (FTD)}

ALS is a progressive and fatal neurodegenerative disease featured by selective loss of both upper and lower motor neurons [120]. FTD is a common type of dementia in people under 65 years of age and may occur in combination with ALS. Although ALS and FTD differ in some clinical symptoms and neuropathological changes, they are recognised to form a broad neurodegenerative continuum [121]. It is now clear that the molecular genetics of ALS and FTD also overlap significantly, involving overexpression of TAR DNA-binding protein (TARDBP), FUS, hnRNPA1, Coiled-Coil-Helix-Coiled-Coil-Helix Domain Containing 10 (CHCHD10), and most importantly, the chromosome 9 open reading frame 72 (C9ORF72) gene [122]. The hexanucleotide G4C2 repeat expansion in the first intron or promoter region of C9ORF72 is now known to be the most common genetic cause for ALS and FTD. The main disease mechanisms are typically split into three mechanisms: gain-of-function due to the toxic dipeptiderepeat proteins produced by non-AUG-initiated translation, gain-of-function from the accumulation of sense and antisense hexanucleotide G4C2 in RNA, and loss-of-function of C9ORF72 through haploinsufficiency [123]. The RNA and dipeptide repeats form insoluble foci in multiple regions within the brain and often co-localise with various RNA-binding proteins [124]. Alternative selection of transcription start and termination sites gives rise to three C9ORF72 RNA transcripts, leading to three protein variants [125]. Aberrant splicing of the expanded C9ORF72 transcript may contribute to its cytotoxicity; however, the expansions have also been shown to form RNA G-quadruplex inclusions and sequester splicing factor hnRNP $\mathrm{H}$ to disrupt splicing in ALS brains [126].

Another ALS- and FTD-related gene that regulates RNA splicing of hnRNPs is the TARDBP gene, which encodes the TAR DNA-binding protein 43 (TDP-43). Pathogenic mutations in TARDBP compromise the function of TDP-43, interfere with $h n R N P A 1$ premRNA splicing and result in inclusion of exon7B and accumulation of the cytotoxic longer form of hnRNP A1B [127]. In addition to the aforementioned causative genes for ALS and FTD, a large number of splicing defects in other genes such as the senataxin $(S E T X)$ and the optineurin $(O P T N)$ genes have also been reported to contribute to disease phenotypes [128-131].

SMA is the leading genetic cause for infant death before the age of 2 years. Unlike other neurodegenerative disorders, SMA is a monogenic disease most 
commonly caused by deletion of the entire SMN1 gene, which encodes the full-length survival motor neuron (SMN) protein [132]. Humans carry one or more copies of $S M N 2$, which is identified as a duplicated unprocessed pseudogene that could potentially be translated into an identical protein to SMN. However, the synonymous $\mathrm{C}>\mathrm{T}$ substitution in SMN2 exon 7 alters an exonic splicing enhancer into an exonic splicing silencer, which predominantly leads to an unstable transcript missing exon 7. Nevertheless, with an increase in SMN2 copy number, small but significant amounts of full-length transcript can be generated and its translation into normal SMN may result in a milder SMA phenotype in some cases [133].

\section{Familial dysautonomia (FD)}

FD or Riley-Day syndrome is a rare genetic neurodegenerative disorder characterised by poor development and progressive degeneration of autonomic and sensory neurons. This disease is almost exclusively found in the Ashkenazi Jewish population [134]. Although non-Jewish cases have been rarely reported, the major haplotype mutation associated with FD is a single point mutation in intron 20 of the inhibitor of kappa light polypeptide $(I K B K A P)$ gene: IVS20+6 T>C [135]. This mutation weakens the 5 ' splice site in IKBKAP intron 20 and results in a frameshift caused by skipping of exon 20. Skipping of the out-of-frame exon 20 results in a premature termination codon in exon 21 , inducing nonsense-mediated decay of the IKBKAP transcript [136]. As IKBKAP is involved in the development and survival of peripheral neurons, depletion of this protein results in progressive degeneration of autonomic and sensory neurons [137].

\section{Expansion diseases}

To date, more than 40 diseases have been linked to expansions of microsatellites at various intragenic regions, leading to various mechanisms of disease [138141]. The most common mechanism in neurodegenerative expansion diseases is the toxic gain-offunction, leading to protein misfolding and insoluble protein aggregation, a hallmark of neurogenerative diseases [8]. Although protein misfolding is the most common phenotypic event, aberrant splicing has been reported in several expansion diseases such as Huntington's disease and the spinocerebellar ataxias. These events have been excellently reviewed in [142, 143], and although not the focus of the review, it is important to highlight the wide range involvement of aberrant splicing in diseases.

\section{Antisense oligonucleotide (AO)-mediated splice- switching strategies for neurodegenerative diseases}

AOs are single-stranded synthetic nucleic acid analogues that are usually 12-30 nucleotides in length and can be designed to specifically bind to target sequences through Watson-Crick base pairing. AOs can be used to manipulate gene expression through a variety of mechanisms including inducing mRNA decay, modulating splicing, masking microRNA-binding, blocking/increasing translation, etc. The mechanisms of AOs have been recently reviewed [144]. These mechanisms are achieved by targeting various cis-acting gene regulation elements and are typically dependent on their backbone chemistries and base modifications. For example, gapmers that contain a central block of deoxynucleotides flanked by blocks of 2'-O-methyl modified ribonucleotides can induce RNase-H to degrade target mRNAs; whereas fully modified peptide nucleic acids or phosphorodiamidate morpholinos (PMOs) are more suited for use as steric blockers or sterically blocking motifs involved in splicing, protein translation or polyadenylation [145-148]. The main focus of this review is on AO-mediated splicing-switching strategies for neurodegenerative disorders, thus we will not expand on the development of AO chemistries/backbone modifications. Chemical evolution of AOs, its relationship to the mechanisms of $\mathrm{AO}$ action and $\mathrm{AO}$ delivery methods have been discussed in a recent review [149].

AO modification of gene expression was first reported in the study by Zamecnik and Stephenson, in which the ribosomal RNA translation of Rous sarcoma virus was inhibited by a complementary 13-nucleotide DNA molecule in vitro [150], presumably through the induction of RNase-H to degrade the mRNA. Since then, other RNase-H-inducing AOs including Fomivirsen, Mipomersen and Inotersen have been developed and approved by the US Food and Drug Administration (FDA) for the treatment of inherited and acquired diseases. A schematic of the major milestones in $\mathrm{AO}$ drug development and approvals (excluding small interfering RNAs) is shown in Fig. 4. Considerable experience has been gained in the development of splice-switching AOs in the past decade (Fig. 4), and the majority of AOs that have been approved by the FDA are designed to specifically modify the pre-mRNA processing.

\section{Splice-switching AOs}

With the wide recognition of the significance of premRNA splicing in disease pathology, there is a need to understand this process and the ability to manipulate mRNAs for therapeutic outcomes. Splice-switching AOs can be designed to anneal across splice motifs, including exon splicing acceptor/donor sites and/or exon splicing 


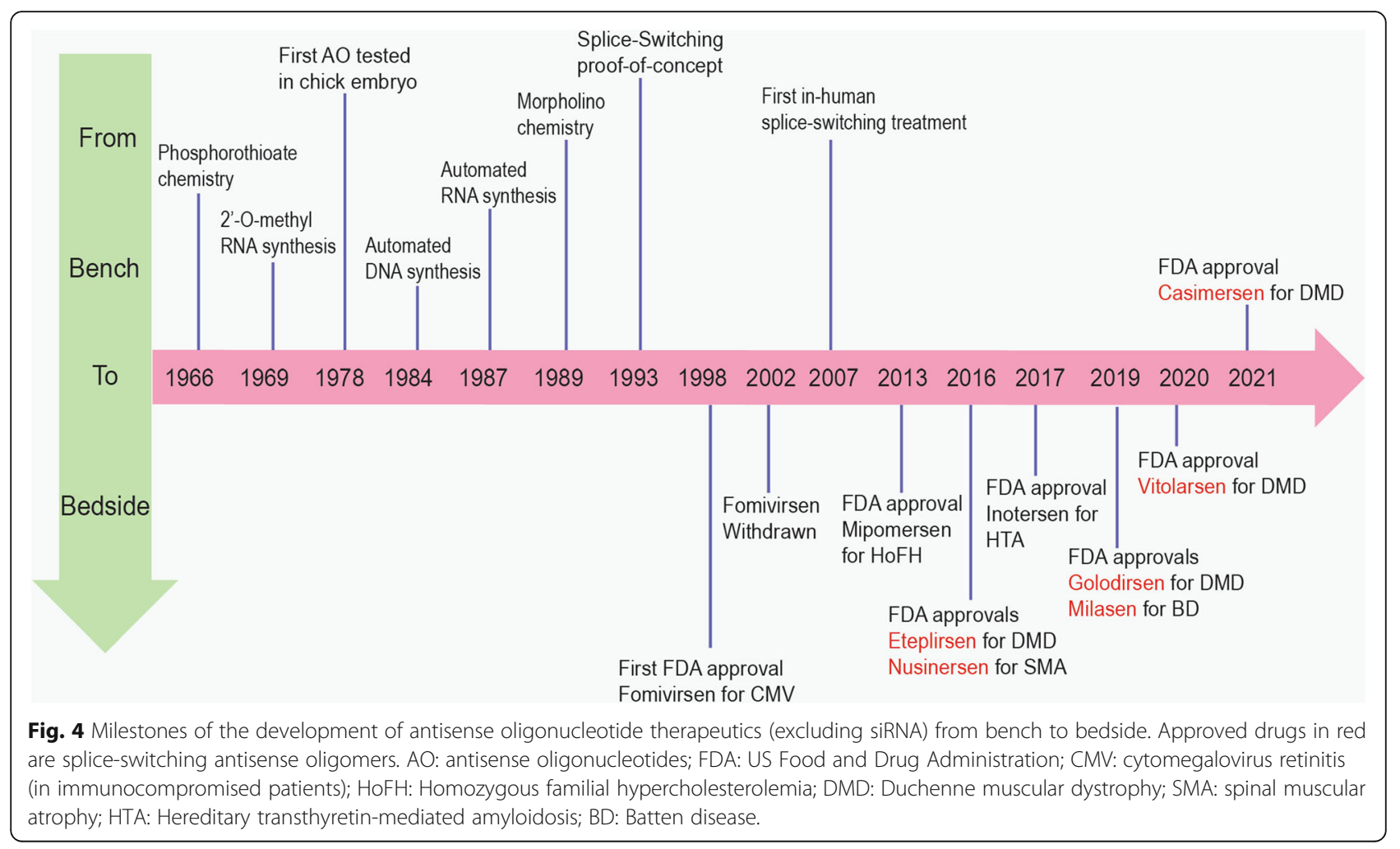

enhancers, to block the interactions between these cisacting elements and trans-acting proteins, thus interfering with pre-mRNA processing (Fig. 5). Although in silico prediction programs can sometimes be of value in designing splice-switching AOs, in our experience an empirical approach is most reliable as described [151]. Nevertheless, no splice motifs have emerged as consistent and reliable $\mathrm{AO}$ targets for efficient $\mathrm{AO}$-mediated splice-switching as shown by previous studies [152-155]. In addition, AO design including the length, base composition and secondary structure has been shown to greatly influence the activity of splice-switching AOs.

Particular AO sequence motifs are also identified to affect $\mathrm{AO}$ activities and cause AO-related toxicities, including stimulating proinflammatory and immune responses. A sequence motif analysis revealed that specific GU-rich 4-mer motifs such as UUGU, GUUC, UGUU and UCUC can activate human Toll-like receptors through inducing the release of proinflammatory cytokines and chemokines from human peripheral blood monocytes [156]. Other factors influencing AO design include the presence, position and number of unmethylated CpG motifs in single-stranded DNA molecules, as they can also bring unwanted effects in addition to the non-specific binding to serum proteins. Polyanionic and negatively charged phosphorothioate AOs are known to bind to proteins, including intracellular and extracellular receptors that can lead to renal and/or hepatic toxicity.
Certain splice-switching AO chemistries, such as PMOs, have been shown to elicit little or no off-target effects in long term, both in vitro and in vivo [157-161].

Although AO chemistries and toxicities have been bottlenecks for AO drug development, recent advances in oligo synthesis (in chemistries, scale and cost of production) have begun to address this hurdle in AO therapeutics (Fig. 4). In recent years, the development of splice-switching therapeutics for some neurodegenerative diseases has been extraordinary. Within the last five years, six splice-switching AO molecules have been approved by the US FDA, four of which are for the treatment of Duchenne muscular dystrophy (DMD). Eteplirsen (Sarepta Therapeutics), a 30-nucleotide PMO, is designed to skip DMD exon 51, Casimersen (Sarepta Therapeutics), is designed to skip DMD exon 45, and Golodirsen (Sarepta Therapeutics) and Viltolarsen (NS Pharma) are designed to skip DMD exon 53 [162-164]. These four drugs now address around 30\% of all DMD mutations. The development of these AO drugs is based on the genotype-phenotype correlations that some exons are not essential regarding the functionality of the dystrophin protein. Although there is heterogeneity in patients with Becker muscular dystrophy (BMD), BMD patients with in-frame deletions in the central rod domain of the dystrophin protein often manifest with milder symptoms compared to DMD caused by out-offrame deletions [165]. Therefore, antisense compounds 


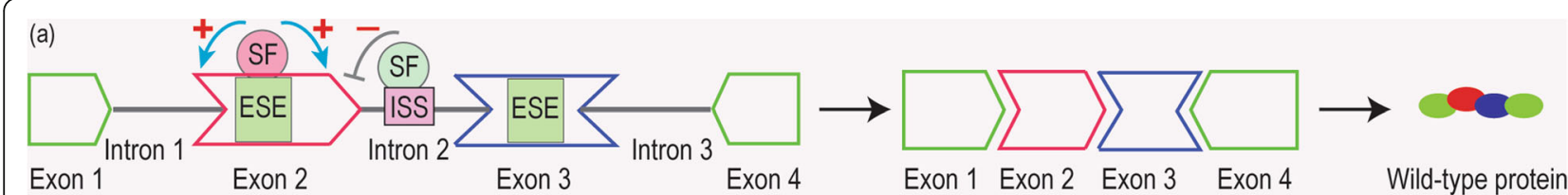

(b)

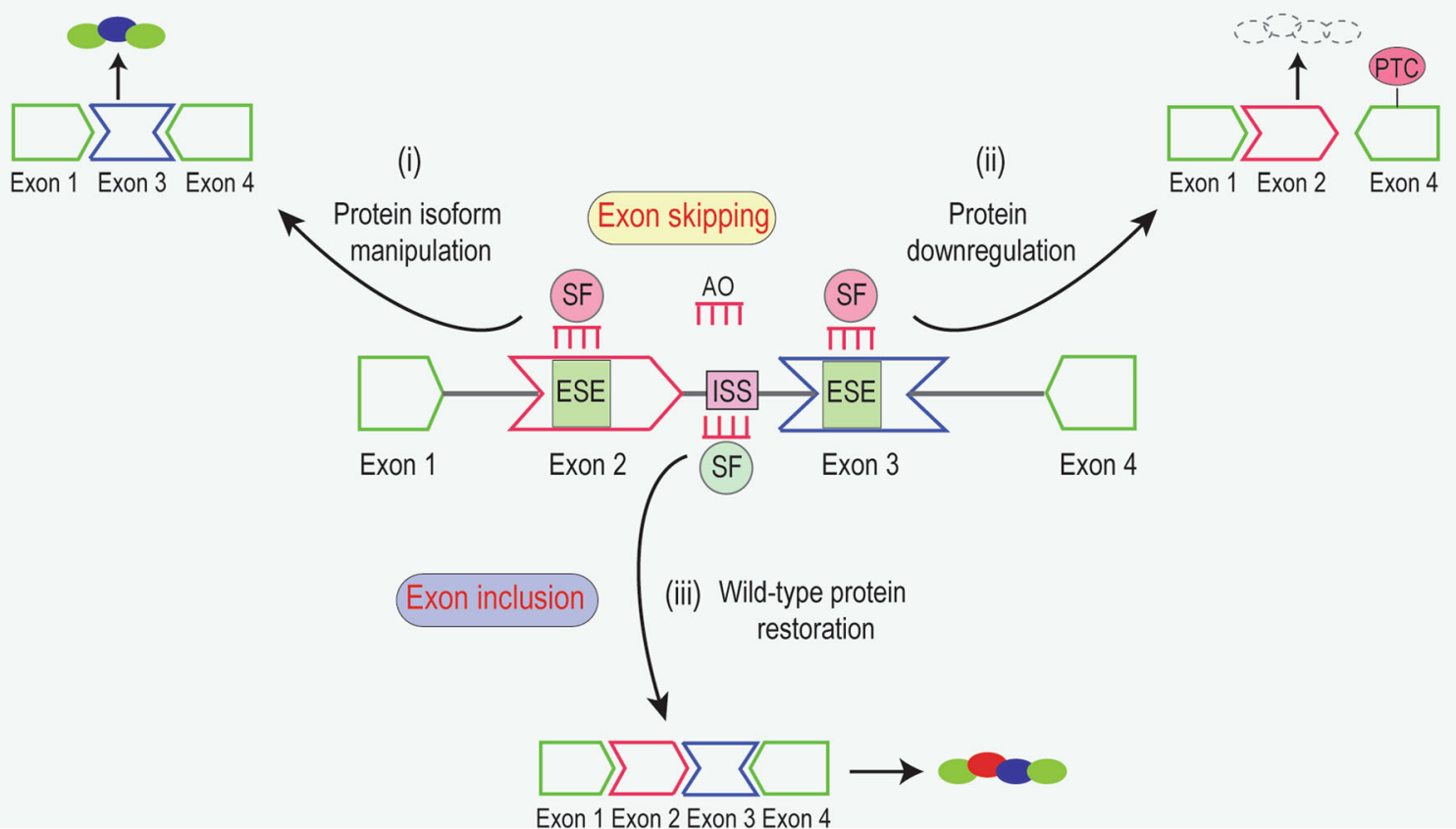

Fig. 5 Mechanisms of action of splice-switching antisense oligonucleotides. a Stimulating splicing factors (SF) shown in pink circles such as SR proteins binding to exon splicing enhancers (ESE) promote the inclusion of an exon, while inhibitory SF in green circles such as hnRNPs binding to intron splicing silencers (ISS) inhibit exon inclusion. When promoting outweighs inhibiting actions, exons are included to generate a full-length transcript and wild-type protein. b Antisense oligomers (AOs) annealing to ESE blocks the interaction between SF and ESE and induces targeted (i) in-frame exon skipping, thus inducing in-frame transcripts and correspondingly new protein isoforms; and (ii) out-of-frame exon skipping and disrupts the reading frame and creates premature stop codon (PTC) in a downstream exon, that may lead to nonsense-mediated mRNA decay of the targeted transcript and downregulation of the protein. (iii) AOs anneal to ISS to increase targeted exon inclusion and generate a full-length transcript and wild-type protein

are designed to block splice enhancers, thus the recognition of targeted DMD exons by spliceosome. Excising exons that flank the DMD-causing out-of-frame exons restores the reading frame and generates a semifunctional, truncated dystrophin protein as a diseasemodifying treatment for DMD.

In addition to the FDA-approved antisense drugs for DMD, Nusinersen, a splice-modulating AO designed to specifically bind to a splicing silencer motif in exon 7 of $S M N 2$, promotes the inclusion of exon 7 and the production of the full-length SMN protein [166]. The C>T substitution in SMN2 creates an exon-splicing silencer and leads to the omission of exon 7 and an unstable SMN protein that is subject to rapid ubiquitinproteasome degradation. By binding to the splicing silencer, Nusinersen blocks the negative elements recognised by trans-acting splicing factors including hnRNPs and inhibits the "looping-out" of SMN2 exon 7 [167], thus producing a full-length, functional SMN protein. Patients with SMA who received intrathecal injections of Nusinersen showed improvements in motor function and required no ventilation assistance, when compared to the placebo cohort in a clinical trial [168]. The positive results from clinical trials then led to the approval of the drug for the treatment of SMA by the US FDA, European Medicines Agency and various medicine administrations in other countries, including China.

Another example showing the rapid development of splice-switching therapies for neurological conditions is the FDA approval of Milasen in 2019. Milasen was approved by the US FDA less than one year after the first contact between scientists and a single patient suffering from Batten's disease [169, 170]. The approval of this "N-of-1" study may lead to regulatory changes and 
encourage a paradigm shift for small-cohort clinical trial design. If a new clinical trial model is established, it would bring huge benefits for the development of AOmediated precision medicine for neurodegenerative disorders. For example, splice-switching strategies targeting one exon of one PD-causing gene will require patients participating in clinical trials to be stratified according to the genetic background, making the target patient cohort very small. Novel regulatory paradigms would, to some extent, facilitate the evaluation of potential spliceswitching therapies for neurodegenerative diseases.

\section{Potential splice-switching therapeutics for PD}

With the mounting evidence of aberrant splicing in PD pathogenesis, recent studies are utilising AOs to correct causative splicing defects in PD patients. Spliceswitching AOs have been designed to induce skipping of $L R R K 2$ exon 2, leading to the generation of a premature stop codon in the transcript. With this strategy, LRRK2 transcript and protein levels are decreased by approximately $50 \%$ and mitophagy function restored in $\mathrm{PD}$ patient fibroblasts carrying the LRRK2 G2019S mutation [171]. Another approach that has been tried to reduce LRRK2 protein is the removal of exon 41. Although only moderate skipping of LRRK2 exon 41 and LRRK2 protein reduction are achieved in vitro, improved calcium homeostasis has been demonstrated in patient iPSCderived neurons with LRRK2 G2019S mutation [172]. Subsequently, a single intracerebroventricular injection of $\mathrm{AO}$ has been shown to induce efficient LRRK2 exon 41 skipping and reduced LRRK2 kinase activity in human LRRK2 transgenic mice [173]. The AO-mediated LRRK2 downregulation strategy is now under a phase I clinical trial as a potential therapeutic approach for LRRK2-related PD [157].

Located within a chromosomal fragile site, genomic deletions are responsible for half of all PARK2 mutations. Clinical genotype-phenotype studies have shown that PD patients carrying the out-of-frame genomic deletions of PARK2 exon 3 or 4 have more severe symptoms and an earlier disease onset than patients harbouring the in-frame genomic deletion of both exons 3 and 4 [174, 175]. In addition, studies mapping the functional domains of the parkin protein have demonstrated that deleting the ubiquitin-like domain and the linker region encoded by PARK2 exons 3 and 4 does not compromise the parkin catalytic activity [176]. These genotype-phenotype correlations justify an approach to excise one of these exons as a potential treatment for patients carrying amenable mutations. Splice-switching AOs targeting the splicing motifs of PARK2 exon 4 have been shown to induce exon 4 skipping and restore functional parkin expression in fibroblasts derived from a PD patient carrying a heterozygous exon 3 deletion [177].
The induced shorter parkin protein can function to maintain mitochondrial homeostasis and transcriptionally repress $p 53$ expression [177]. Although further investigations are needed to prove the efficacy of this approach, this strategy may provide new avenues for $\mathrm{AO}$ mediated treatment of PD.

$\alpha$-Synuclein is another potential target for the development of disease-modifying therapies for synucleinopathies. Manipulating SNCA isoforms with spliceswitching AOs could be an alternative option for PD treatment, since isoforms including SNCA126 and SNCA41 are less likely to form toxic $\alpha$-synuclein aggregates $[77,83]$. $\alpha$-Synuclein pathology has been found to accumulate in anterior olfactory nuclei years prior to the development of motor symptoms [178]. This suggests that switching SNCA isoforms might have to be performed in the prodromal stage of PD to reduce the risk of developing motor symptoms, which poses considerable additional challenges, cost and duration of clinical evaluation.

\section{Potential splice-switching strategies for AD}

Accumulating evidence has supported the central role of $\mathrm{APP}$ and $\mathrm{A} \beta$ in the development of $\mathrm{AD}$, therefore efforts such as $A O$-mediated modulation of $A \beta$, especially $A \beta 42$ expression, are currently under investigation as potential AD treatments [179]. Different antisense strategies targeting APP mRNA have been shown to reduce the APP protein to $39 \%-82 \%$ of normal levels and improve the cognitive functions in a mouse model of AD [180]. Since the exon 17 of $A P P$ encodes the $\gamma$-secretase cleavage site, which generates $A \beta 42$, removing this cleavage site is hypothesised to reduce toxic $A \beta 42$ expression and aggregation. In a recent study, treatment with AOs targeting $A P P$ exon 17 splicing motifs resulted in an APP transcript lacking exon 17 , leading to reduced $A \beta 42$ both in vitro and in vivo [181]. Another gene shown to be upregulated in $\mathrm{AD}$ patient brains is BACE1. A study has demonstrated that AOs designed to skip the out-offrame BACE1 exons can reduce BACE1 expression [182]. However, this study is preliminary, and the AOs used are still in the early stage of development, so further studies are needed to demonstrate the long-term consequences of these novel BACE1-targeting AOs as therapeutic strategies.

Of the three major ApoE isoforms ApoE2, ApoE3 and ApoE4 [183], the E4 isoform is strongly associated with the onset of $\mathrm{AD}$ and disease progression, thus reducing the ApoE4 level is hypothesized to induce reduction of $\mathrm{A} \beta$ accumulation and attenuation of cognitive deficits. An antisense approach has been investigated in an attempt to downregulate the disease-susceptible ApoE4 isoform in neonatal mice, resulting in a significant reduction of the initiation of $A \beta$ accumulation and $A \beta$ 
plaque size [184]. Although the exact mechanisms of how ApoE4 affects $A \beta$ metabolism and increases $A D$ risk remain to be determined, the ApoE receptor 2 (ApoER2) appears to mediate the pathological synergistic interactions between ApoE4 and A $\beta$ [117]. Since dysregulated splicing of ApoER2 exon 19 has been observed in brain samples from AD patients, the splice-switching AO strategies have been used to enhance exon 19 skipping and have been shown to improve synaptic function and memory in an AD mouse model [185].

Another approach has been to target tau expression levels. A splice-switching strategy aiming to excise $M A P T$ exon 10 and thereby convert $4 \mathrm{R}$ tau to $3 \mathrm{R}$ tau offers an alternative strategy to alleviate the tauopathy. This splice-switching approach is likely to be less toxic as it would only shift the relative ratio of the two isoforms to confer a more protective effect, rather than complete downregulation of all isoforms.

\section{Splice-switching approaches for other neurodegenerative disorders}

Several pathogenic mechanisms of expanded C9ORF72 have been implicated in ALS and FTD diseases, hence reducing the repeat expansions is being considered as a potential treatment for patients. In addition to the allelespecific knockdown of the expanded C9ORF72 allele [186], reducing C9ORF72 expression using spliceswitching AOs to skip out-of-frame exons similar to that depicted in Fig. 5b(ii) could also downregulate C9ORF72. However, reducing the levels of the nonexpanded transcripts could lead to autophagy deficits [187]. Since the disease-associated repeat expansion is only present in the C9ORF72 transcript starting with exon 1a [125], altering the C9ORF72 transcription start site could be another possible approach as indicated by a recent study showing $\mathrm{AO}$ induction of transcriptional blocking [188]. Similar strategies can also be considered for patients with other microsatellite repeat expansion disorders including spinocerebellar ataxia type 3 (SCA3), Huntington's disease, spinal bulbar muscular atrophy and fragile $\mathrm{X}$ syndrome, although the location, length and the repeating units of these microsatellite repeat expansions may vary [189]. For example, the CAG repeat expansion is located in ATXN3 exon 10 (the causative gene for SCA3); and various splice-switching AOs have been tried to remove the repeat expansion containing exon 10 and reduce the polyglutamine-expanded Ataxin-3 protein both in vitro and in vivo $[155,190]$.

Recently, two ALS patients who received intrathecal administration of an adeno-associated virus encoding a microRNA targeting the superoxide dismutase type 1 (SOD1) gene had transient improvement in leg strength and a stable vital capacity during a 12-month follow-up period [191], suggesting the therapeutic benefits of downregulating SOD1. The splice-switching strategy (Fig. 5b(ii)) based on an FDA-approved chemistry is an alternative approach to knockdown SOD1. By skipping an out-of-frame SOD1 exon, a different SOD1 transcript isoform is generated with a premature stop codon, which is subjected to nonsense-mediated decay and thus decreasing SOD1 protein expression [192].

Since most neurodegenerative disorders have highly complicated aetiologies and relatively slow pathogenesis where mutations in multiple genes are involved, spliceswitching AOs targeting one gene or one mRNA isoform are likely to be applicable to only a certain proportion of patients with these diseases. For example, mutations in FUS make up only $2.8 \%-6.4 \%$ of familial ALS cases (familial cases only account for $10 \%$ of all ALS patients), thus correcting these mutations by AOs would only address a small ALS population, creating challenges for clinical trial design. However, since the FDA approval of the "N-of-1" study for Batten's disease, regulatory changes have been made, increasing the likelihood that personalised medicine may become available for individuals or small populations with rare diseases and highly amenable mutations.

\section{Conclusions}

AOs, especially splice-switching AOs, have the capacity and potential to reduce, restore or manipulate the expression of mRNAs and their translated proteins with high specificity. Thus, they can be used to target a variety of diseases, in particular neurodegenerative diseases where abnormal, or inappropriate splicing defects are especially common. The delivery of AOs to the central nervous system is further improving with the advancement in $\mathrm{AO}$ chemical modifications and delivery carriers which include cell-penetrating peptides and polymerbased nanoparticles. Unlike the viral vector-mediated siRNA approaches or gene therapy, regular AO administrations are needed to maintain long-term therapeutic benefits, and this comes with both advantages and disadvantages. The application of these AOs does not constitute gene therapy in the usual sense as the genome of the patient is not modified, but gene expression is specifically altered. Although re-administration is required, AO delivery can be readily withdrawn if adverse effects are encountered, or a more effective treatment becomes available. For example, DMD individuals receiving weekly infusions of Eteplirsen, Golodirsen, Viltolarsen or Casimersen could easily transfer across to one of the viral gene replacement therapies upon validation of the safety and efficacy of a therapy that is not restricted to a specific subset of mutations. Unfortunately, a recent clinical trial update failed to show the efficacy of one gene therapy for DMD patients. The development of most AO-mediated splice-switching approaches is at a 
very early stage and it has the ability to change the landscape of precision medicine for neurodegenerative disorders. Although huge efforts are needed to overcome the challenges ahead, including animal modelling for preclinical studies and clinical trial design for subsets of patients when personalised medicine is considered, the emerging splice-switching therapeutics could be a game changer in the development of disease-modifying treatments for neurodegenerative disorders.

\section{Abbreviations \\ $A \beta$ : Amyloid- $\beta$; AD: Alzheimer's disease; ALS: Amyotrophic lateral sclerosis; AO: Antisense oligonucleotides; DMD: Duchenne muscular dystrophy; FD: Familial dysautonomia; FDA: Food and Drug Administration; FTD: Frontotemporal dementia; ISS: Intron splicing silencers; PD: Parkinson's disease; PMO: Phosphorodiamidate morpholino oligomers; PTC: Premature stop codon; SCA: Spinocerebellar ataxia; SMA: Spinal muscular atrophy; SMN: Survival motor neuron; SNP: Single nucleotide polymorphisms; snRNA: Small nuclear RNAs; snRNPs: Small nuclear ribonucleoproteins; tKO: Triple knockout; UTR: Untranslated region}

\section{Acknowledgements}

Not applicable.

\section{Authors' contributions}

$\mathrm{DL}$ and $\mathrm{CM}$ conceived the paper. $\mathrm{DL}, \mathrm{CM}$ and MA wrote the paper. MA, FM and SW reviewed and edited the manuscript. All authors read and approved the manuscript.

\section{Funding}

This work was funded by the Australian National Health and Medical Research Council, grant number AP1144791.

\section{Availability of data and materials}

Not applicable.

\section{Declarations}

\section{Ethics approval and consent to participate}

Not applicable.

\section{Consent for publication}

Not applicable.

\section{Competing interests}

SDW is a consultant to Sarepta Therapeutics. He is named as an inventor on patents licensed through the University of Western Australia to Sarepta Therapeutics, and as such is entitled to milestone and royalty payments. DHL, CSM and MATH salaries are partly funded by Sarepta Therapeutics.

Received: 15 December 2020 Accepted: 23 April 2021

Published online: 20 May 2021

\section{References}

1. Evers MM, Toonen $L$, van Roon-Mom WM. Antisense oligonucleotides in therapy for neurodegenerative disorders. Adv Drug Del Rev. 2015;87:90-103.

2. Guo JL, Lee VM. Cell-to-cell transmission of pathogenic proteins in neurodegenerative diseases. Nat Med. 2014;20(2):130-8.

3. Gusella JF, MacDonald ME. Molecular genetics: unmasking polyglutamine triggers in neurodegenerative disease. Nat Rev Neurosci. 2000;1 (2):109-15.

4. Mills JD, Janitz M. Alternative splicing of mRNA in the molecular pathology of neurodegenerative diseases. Neurobiol Aging. 2012;33(5):1012.e11-24.

5. Taylor JP, Hardy J, Fischbeck KH. Toxic proteins in neurodegenerative disease. Science. 2002;296(5575):1991-5.

6. Skovronsky DM, Lee VMY, Trojanowski JQ. Neurodegenerative diseases: new concepts of pathogenesis and their therapeutic implications. Annu Rev Pathol Mech Dis. 2006;1:151-70.

7. Ross CA, Poirier MA. Protein aggregation and neurodegenerative disease. Nat Med. 2004;10(7):S10-7.
8. Sweeney P, Park H, Baumann M, Dunlop J, Frydman J, Kopito R, et al. Protein misfolding in neurodegenerative diseases: implications and strategies. Transl Neurodegener. 2017;6(1):1-13.

9. Zeineddine R, Yerbury JJ. The role of macropinocytosis in the propagation of protein aggregation associated with neurodegenerative diseases. Front Physiol. 2015;6:277.

10. Zoghbi HY, Orr HT. Pathogenic mechanisms of a polyglutamine-mediated neurodegenerative disease, spinocerebellar ataxia type 1. J Biol Chem. 2009; 284(12):7425-9.

11. Consortium IWGS. A chromosome-based draft sequence of the hexaploid bread wheat (Triticum aestivum) genome. Science. 2014;345(6194):1251788.

12. Neale DB, Wegrzyn JL, Stevens KA, Zimin AV, Puiu D, Crepeau MW, et al. Decoding the massive genome of loblolly pine using haploid DNA and novel assembly strategies. Genome Biol. 2014;15(3):1-13.

13. Keren H, Lev-Maor G, Ast G. Alternative splicing and evolution: diversification, exon definition and function. Nat Rev Genet. 2010;11 (5):345-55.

14. Kelemen O, Convertini P, Zhang Z, Wen Y, Shen M, Falaleeva M, et al. Function of alternative splicing. Gene. 2013;514(1):1-30.

15. Douglas AG, Wood MJ. RNA splicing: disease and therapy. Brief Funct Genomics. 2011;10(3):151-64.

16. Sperling R. The nuts and bolts of the endogenous spliceosome. Wiley Interdiscip Rev RNA. 2017:8(1):e1377.

17. Staley JP, Woolford JL Jr. Assembly of ribosomes and spliceosomes: complex ribonucleoprotein machines. Curr Opin Cell Biol. 2009;21(1):109-18

18. Will CL, Lührmann R. Spliceosome structure and function. Cold Spring Harb Perspect Biol. 2011;3(7):a003707.

19. Pitout I. Modulation of modifiers of pre-mRNA splicing: a therapeutic strategy for amenable inherited diseases. PhD thesis,. Perth, Australia: Murdoch University; 2018 ,

20. Ward AJ, Cooper TA. The pathobiology of splicing. J Pathol. 2010;220(2): 152-63.

21. Daguenet E, Dujardin G, Valcárcel J. The pathogenicity of splicing defects: mechanistic insights into pre-mRNA processing inform novel therapeutic approaches. EMBO Rep. 2015;16(12):1640-55.

22. Baralle FE, Giudice J. Alternative splicing as a regulator of development and tissue identity. Nat Rev Mol Cell Biol. 2017:18(7):437.

23. Kalea AZ, Schmidt AM, Hudson BI. Alternative splicing of RAGE: roles in biology and disease. Front Biosci. 2011:17:2756-70.

24. Jules J, Maiguel D, Hudson BI. Alternative splicing of the RAGE cytoplasmic domain regulates cell signaling and function. PLoS One. 2013:8(11):e78267.

25. Ding Q, Keller JN. Splice variants of the receptor for advanced glycosylation end products (RAGE) in human brain. Neurosci Lett. 2004;373(1):67-72.

26. De Conti L, Baralle M, Buratti E. Exon and intron definition in pre-mRNA splicing. Wiley Interdiscip Rev RNA. 2013;4(1):49-60.

27. Sumanasekera C, Kelemen O, Beullens M, Aubol BE, Adams JA, Sunkara M, et al. C6 pyridinium ceramide influences alternative pre-mRNA splicing by inhibiting protein phosphatase-1. Nucleic Acids Res. 2012;40(9):4025-39.

28. Kondo $\mathrm{S}$, Yamamoto N, Murakami T, Okumura M, Mayeda A, Imaizumi K. Tra2 $\beta$, SF2/ASF and SRp30c modulate the function of an exonic splicing enhancer in exon 10 of tau pre-mRNA. Genes Cells. 2004;9(2):121-30.

29. Tazi J, Bakkour N, Stamm S. Alternative splicing and disease. Biochim Biophys Acta. 2009;1792(1):14-26.

30. Hammond SM, Wood MJ. Genetic therapies for RNA mis-splicing diseases. Trends Genet. 2011;27(5):196-205.

31. Scotti MM, Swanson MS. RNA mis-splicing in disease. Nat Rev Genet. 2016; 17(1):19.

32. Fiszbein $A$, Giono $L E$, Quaglino A, Berardino BG, Sigaut L, Von Bilderling $C$, et al. Alternative splicing of G9a regulates neuronal differentiation. Cell Rep. 2016;14(12):2797-808.

33. Jacko M, Weyn-Vanhentenryck SM, Smerdon JW, Yan R, Feng H, Williams DJ, et al. Rbfox splicing factors promote neuronal maturation and axon initial segment assembly. Neuron. 2018;97(4):853-68. e6.

34. Lipscombe D, Andrade A, Allen SE. Alternative splicing: functional diversity among voltage-gated calcium channels and behavioral consequences. Biochim Biophy Acta. 2013;1828(7):1522-9.

35. Lipscombe D, Soto EJL. Alternative splicing of neuronal genes: new mechanisms and new therapies. Curr Opin Neurobiol. 2019;57:26-31.

36. Kornberg RD. RNA polymerase II transcription control. Trends Biochem Sci. 1996;21(9):325-6.

37. Kornblihtt AR, de la Mata M, Fededa JP, Munoz MJ, Nogues G. Multiple links between transcription and splicing. RNA. 2004;10(10):1489-98. 
38. Jelen N, Ule J, Živin M, Darnell RB. Evolution of Nova-dependent splicing regulation in the brain. PLoS Genet. 2007;3(10):e173.

39. Kremerskothen J, Teber I, Wendholt D, Liedtke T, Böckers TM, Barnekow A. Brain-specific splicing of a-actinin 1 (ACTN1) mRNA. Biochem Biophys Res Commun. 2002;295(3):678-81.

40. Madgwick A, Fort P, Hanson PS, Thibault P, Gaudreau M-C, Lutfalla G, et al. Neural differentiation modulates the vertebrate brain specific splicing program. PLoS One. 2015;10(5):e0125998.

41. Turman CM, Hatley JM, Ryder DJ, Ravindranath V, Strobel HW. Alternative splicing within the human cytochrome P450 superfamily with an emphasis on the brain: The convolution continues. Expert Opin Drug Metab Toxicol. 2006;2(3):399-418.

42. Ule J, Darnell RB. Functional and mechanistic insights from genome-wide studies of splicing regulation in the brain. Adv Exp Med Biol. 2007;623:148-60.

43. Black D, Grabowski P. Alternative pre-mRNA splicing and neuronal function. Prog Mol Subcell Biol. 2003;31:187-216.

44. Lipscombe D. Neuronal proteins custom designed by alternative splicing. Curr Opin Neurobiol. 2005;15(3):358-63.

45. Porter RS, Jaamour F, Iwase S. Neuron-specific alternative splicing of transcriptional machineries: Implications for neurodevelopmental disorders. Mol Cell Neurosci. 2018;87:35-45.

46. Singh NK, Singh NN, Androphy EJ, Singh RN. Splicing of a critical exon of human Survival Motor Neuron is regulated by a unique silencer element located in the last intron. Mol Cell Biol. 2006;26(4):1333-46.

47. Matlin AJ, Clark F, Smith CW. Understanding alternative splicing: towards a cellular code. Nat Rev Mol Cell Biol. 2005;6(5):386-98.

48. Stamm S, Ben-Ari S, Rafalska I, Tang Y, Zhang Z, Toiber D, et al. Function of alternative splicing. Gene. 2005;344:1-20.

49. Black DL. Mechanisms of alternative pre-messenger RNA splicing. Annu Rev Biochem. 2003;72(1):291-336.

50. Heinzen EL, Ge D, Cronin KD, Maia JM, Shianna KV, Gabriel WN, et al. Tissuespecific genetic control of splicing: implications for the study of complex traits. PLOS Biol. 2008;6(12):e1000001.

51. Busch A, Hertel KJ. Evolution of SR protein and hnRNP splicing regulatory factors. Wiley Interdiscip Rev: RNA. 2012;3(1):1-12.

52. Furlanis E, Traunmüller L, Fucile G, Scheiffele P. Landscape of ribosomeengaged transcript isoforms reveals extensive neuronal-cell-class-specific alternative splicing programs. Nat Neurosci. 2019;22(10):1709-17.

53. Vuong CK, Black DL, Zheng S. The neurogenetics of alternative splicing. Nat Rev Neurosci. 2016;17(5):265-81.

54. Coutinho-Mansfield GC, Xue Y, Zhang Y, Fu XD. PTB/nPTB switch: a posttranscriptional mechanism for programming neuronal differentiation. Genes Dev. 2007;21(13):1573-7.

55. Makeyev EV, Zhang J, Carrasco MA, Maniatis T. The microRNA miR-124 promotes neuronal differentiation by triggering brain-specific alternative pre-mRNA splicing. Mol Cell. 2007;27(3):435-48.

56. Mokabber H, Najafzadeh N, Mohammadzadeh VM. miR-124 promotes neural differentiation in mouse bulge stem cells by repressing Ptbp1 and Sox9. J Cell Physiol. 2019;234(6):8941-50.

57. Ling JP, Chhabra R, Merran JD, Schaughency PM, Wheelan SJ, Corden JL, et al. PTBP1 and PTBP2 repress nonconserved cryptic exons. Cell Rep. 2016; 17(1):104-13.

58. Quesnel-Vallières M, Irimia M, Cordes SP, Blencowe BJ. Essential roles for the splicing regulator nSR100/SRRM4 during nervous system development. Genes Dev. 2015:29(7):746-59.

59. Ohnishi T, Shirane M, Nakayama KI. SRRM4-dependent neuron-specific alternative splicing of protrudin transcripts regulates neurite outgrowth. Sci Rep. 2017;7:41130.

60. Irimia M, Weatheritt RJ, Ellis JD, Parikshak NN, Gonatopoulos-Pournatzis T, Babor $\mathrm{M}$, et al. A highly conserved program of neuronal microexons is misregulated in autistic brains. Cell. 2014;159(7):1511-23.

61. Raj B, Irimia M, Braunschweig U, Sterne-Weiler T, O'Hanlon D, Lin ZY, et al. A global regulatory mechanism for activating an exon network required for neurogenesis. Mol Cell. 2014;56(1):90-103.

62. Meldolesi J. Alternative splicing by NOVA factors: from gene expression to cell physiology and pathology. Int J Mol Sci. 2020;21(11):3941.

63. Yano M, Hayakawa-Yano Y, Mele A, Darnell RB. Nova2 regulates neuronal migration through an RNA switch in disabled-1 signaling. Neuron. 2010; 66(6):848-58.

64. Bock HH, May P. Canonical and non-canonical Reelin signaling. Front Cell Neurosci. 2016;10:166.
65. Förster E, Jossin Y, Zhao S, Chai X, Frotscher M, Goffinet AM. Recent progress in understanding the role of Reelin in radial neuronal migration, with specific emphasis on the dentate gyrus. Eur J Neurosci. 2006;23(4):9019.

66. Perez-Garcia CG, Tissir F, Goffinet AM, Meyer G. Reelin receptors in developing laminated brain structures of mouse and human. Eur J Neurosci. 2004;20(10):2827-32

67. Förster E, Bock HH, Herz J, Chai X, Frotscher M, Zhao S. Emerging topics in Reelin function. Eur J Neurosci. 2010;31(9):1511-8.

68. Li Q, Lee JA, Black DL. Neuronal regulation of alternative pre-mRNA splicing. Nat Rev Neurosci. 2007:8(11):819-31.

69. Li Q, Zheng S, Han A, Lin CH, Stoilov P, Fu XD, et al. The splicing regulator PTBP2 controls a program of embryonic splicing required for neuronal maturation. Elife. 2014;3:e01201.

70. Gehman LT, Stoilov P, Maguire J, Damianov A, Lin CH, Shiue L, et al. The splicing regulator Rbfox1 (A2BP1) controls neuronal excitation in the mammalian brain. Nat Genet. 2011:43(7):706-11.

71. Gehman LT, Meera P, Stoilov P, Shiue L, O'Brien JE, Meisler MH, et al. The splicing regulator Rbfox 2 is required for both cerebellar development and mature motor function. Genes Dev. 2012;26(5):445-60.

72. Lee JA, Damianov $\mathrm{A}$, Lin $\mathrm{CH}$, Fontes $\mathrm{M}$, Parikshak NN, Anderson ES, et al. Cytoplasmic Rbfox1 regulates the expression of synaptic and autism-related genes. Neuron. 2016;89(1):113-28.

73. Ghiglieri V, Calabrese V, Calabresi P. Alpha-synuclein: from early synaptic dysfunction to neurodegeneration. Front Neurol. 2018;9:295.

74. Hou X, Watzlawik JO, Fiesel FC, Springer W. Autophagy in Parkinson's disease. J Mol Biol. 2020:432(8):2651-72.

75. Soll LG, Eisen JN, Vargas K, Medeiros AT, Hammar KM, Morgan JR. aSynuclein-112 impairs synaptic vesicle recycling consistent with its enhanced membrane binding properties. Front Cell Dev Biol. 2020;8:405.

76. Vicario M, Cieri D, Brini M, Cali T. The close encounter between alphasynuclein and mitochondria. Front Neurosci. 2018:12:388.

77. Gámez-Valero A, Beyer K. Alternative splicing of alpha-and beta-synuclein genes plays differential roles in synucleinopathies. Genes. 2018;9(2):63.

78. Je G, Guhathakurta S, Yun SP, Ko HS, Kim YS. A novel extended form of alpha-synuclein 3'UTR in the human brain. Mol Brain. 2018;11(1):29.

79. Tseng E, Rowell WJ, Glenn OC, Hon T, Barrera J, Kujawa S, et al. The landscape of SNCA transcripts across synucleinopathies: new insights from long reads sequencing analysis. Front Genet. 2019;10:584.

80. Kaji S, Maki T, Ishimoto T, Yamakado H, Takahashi R. Insights into the pathogenesis of multiple system atrophy: focus on glial cytoplasmic inclusions. Transl Neurodegener. 2020;9:7.

81. Oueslati A. Implication of alpha-synuclein phosphorylation at S129 in synucleinopathies: What have we learned in the last decade? J Parkinsons Dis. 2016;6(1):39-51.

82. Braak H, Ghebremedhin E, Rüb U, Bratzke H, Del Tredici K. Stages in the development of Parkinson's disease-related pathology. Cell Tissue Res. 2004; 318(1):121-34

83. Vinnakota RL, Yedlapudi D, Manda KM, Bhamidipati K, Bommakanti KT, RangaLakshmi GS, et al. Identification of an alternatively spliced a-synuclein isoform that generates a 41-amino acid N-terminal truncated peptide, 41-syn: role in dopamine homeostasis. ACS Chem Neurosci. 2018;9(12):2948-58.

84. Krupenko SA, Horita DA. The role of single-nucleotide polymorphisms in the function of candidate tumor suppressor ALDH1L1. Front Genet. 2019;10: 1013.

85. Soldner F, Stelzer Y, Shivalila CS, Abraham BJ, Latourelle JC, Barrasa MI, et al. Parkinson-associated risk variant in distal enhancer of a-synuclein modulates target gene expression. Nature. 2016;533(7601):95-9.

86. Guhathakurta S, Bok E, Evangelista BA, Kim YS. Deregulation of a-synuclein in Parkinson's disease: Insight from epigenetic structure and transcriptional regulation of SNCA. Prog Neurobiol. 2017;154:21-36.

87. McCarthy JJ, Linnertz C, Saucier L, Burke JR, Hulette CM, Welsh-Bohmer KA, et al. The effect of SNCA $3^{\prime}$ region on the levels of SNCA-112 splicing variant. Neurogenetics. 2011;12(1):59-64.

88. Campêlo CLC, Cagni FC, de Siqueira FD, Oliveira LG Jr, Silva-Neto AB, Macêdo PT, et al. Variants in SNCA gene are associated with Parkinson's disease risk and cognitive symptoms in a Brazilian sample. Front Aging Neurosci. 2017:9:198

89. Barrie ES, Lee SH, Frater JT, Kataki M, Scharre DW, Sadee W. Alpha-synuclein mRNA isoform formation and translation affected by polymorphism in the human SNCA 3'UTR. Mol Genet Genomic Med. 2018;6(4):565-74. 
90. Chiba-Falek O. Structural variants in SNCA gene and the implication to synucleinopathies. Curr Opin Genet Dev. 2017;44:110-6.

91. Beyer K, Humbert J, Ferrer A, Lao Jl, Latorre P, Lopez D, et al. A variable poly-T sequence modulates alpha-synuclein isoform expression and is associated with aging. J Neurosci Res. 2007;85(7):1538-46.

92. Tolosa E, Vila M, Klein C, Rascol O. LRRK2 in Parkinson disease: challenges of clinical trials. Nat Rev Neurol. 2020;16(2):97-107.

93. La Cognata V, D'Agata V, Cavalcanti F, Cavallaro S. Splicing: is there an alternative contribution to Parkinson's disease? Neurogenetics. 2015;16(4): 245-63.

94. Tan SH, Karri V, Tay NWR, Chang KH, Ah HY, Ng PQ, et al. Emerging pathways to neurodegeneration: Dissecting the critical molecular mechanisms in Alzheimer's disease, Parkinson's disease. Biomed Pharmacother. 2019;111:765-77.

95. Du X, Wang X, Geng M. Alzheimer's disease hypothesis and related therapies. Transl Neurodegener. 2018;7:2.

96. Sealey MA, Vourkou E, Cowan CM, Bossing T, Quraishe S, Grammenoudi S, et al. Distinct phenotypes of three-repeat and four-repeat human tau in a transgenic model of tauopathy. Neurobiol Dis. 2017;105:74-83.

97. Mandelkow EM, Schweers O, Drewes G, Biernat J, Gustke N, Trinczek B, et al. Structure, microtubule interactions, and phosphorylation of tau protein. Ann N Y Acad Sci. 1996;777:96-106.

98. Alonso AD, Cohen LS, Corbo C, Morozova V, Elldrissi A, Phillips G, et al. Hyperphosphorylation of Tau associates with changes in its function beyond microtubule stability. Front Cell Neurosci. 2018;12:338.

99. Strang KH, Golde TE, Giasson BI. MAPT mutations, tauopathy, and mechanisms of neurodegeneration. Lab Invest. 2019;99(7):912-28.

100. Qian W, Liu F. Regulation of alternative splicing of tau exon 10. Neurosc Bull. 2014;30(2):367-77.

101. Sims R, Hill M, Williams J. The multiplex model of the genetics of Alzheimer's disease. Nat Neurosci. 2020;23(3):311-22.

102. Scheltens P, Blennow K, Breteler MM, de Strooper B, Frisoni GB, Salloway S, et al. Alzheimer's disease. Lancet. 2016;388(10043):505-17.

103. Gan CL, Zhang T, Lee TH. The genetics of Alzheimer's disease in the Chinese population. Int J Mol Sci. 2020;21(7):2381.

104. Wang X, Zhou X, Li G, Zhang Y, Wu Y, Song W. Modifications and trafficking of APP in the pathogenesis of Alzheimer's disease. Front Mol Neurosci. 2017;10:294.

105. Arber C, Toombs J, Lovejoy C, Ryan NS, Paterson RW, Willumsen N, et al. Familial Alzheimer's disease patient-derived neurons reveal distinct mutationspecific effects on amyloid beta. Mol Psychiatry. 2020;25(11):2919-31.

106. Kelleher RJ 3rd, Shen J. Presenilin-1 mutations and Alzheimer's disease. Proc Natl Acad Sci U S A. 2017;114(4):629-31.

107. Sun L, Zhou R, Yang G, Shi Y. Analysis of 138 pathogenic mutations in presenilin- 1 on the in vitro production of $A \beta 42$ and $A \beta 40$ peptides by $Y$ secretase. Proc Natl Acad Sci U S A. 2017;114(4):E476-e85.

108. Ramirez Aguilar L, Acosta-Uribe J, Giraldo MM, Moreno S, Baena A, Alzate D, et al. Genetic origin of a large family with a novel PSEN1 mutation (lle416Thr). Alzheimers Dement. 2019;15(5):709-19.

109. Rovelet-Lecrux A, Charbonnier C, Wallon D, Nicolas G, Seaman MN, Pottier $C$, et al. De novo deleterious genetic variations target a biological network centered on $A \beta$ peptide in early-onset Alzheimer disease. Mol Psychiatry. 2015;20(9):1046-56.

110. Perrone F, Cacace R, Van Mossevelde S, Van den Bossche T, De Deyn PP, Cras $P$, et al. Genetic screening in early-onset dementia patients with unclear phenotype: relevance for clinical diagnosis. Neurobiol Aging. 2018; 69:292.e7-92.e14.

111. Jayadev S, Leverenz JB, Steinbart E, Stahl J, Klunk W, Yu CE, et al. Alzheimer's disease phenotypes and genotypes associated with mutations in presenilin 2. Brain. 2010;133(Pt 4):1143-54

112. Braggin JE, Bucks SA, Course MM, Smith CL, Sopher B, Osnis L, et al. Alternative splicing in a presenilin 2 variant associated with Alzheimer disease. Ann Clin Transl Neurol. 2019;6(4):762-77.

113. Ebrahimie E, Moussavi Nik SH, Newman M, Van Der Hoek M, Lardelli M. The zebrafish equivalent of Alzheimer's disease-associated PRESENILIN isoform PS2V regulates inflammatory and other responses to hypoxic stress. J Alzheimers Dis. 2016;52(2):581-608.

114. Moussavi Nik SH, Newman M, Wilson L, Ebrahimie E, Wells S, Musgrave I, et al. Alzheimer's disease-related peptide PS2V plays ancient, conserved roles in suppression of the unfolded protein response under hypoxia and stimulation of $\gamma$-secretase activity. Hum Mol Genet. 2015;24(13):3662-78.
115. Williams T, Borchelt DR, Chakrabarty P. Therapeutic approaches targeting Apolipoprotein E function in Alzheimer's disease. Mol Neurodegener. 2020; 15(1):8.

116. Safieh M, Korczyn AD, Michaelson DM. ApoE4: an emerging therapeutic target for Alzheimer's disease. BMC Med. 2019;17(1):64.

117. Gilat-Frenkel M, Boehm-Cagan A, Liraz O, Xian X, Herz J, Michaelson DM. Involvement of the Apoer2 and Lrp1 receptors in mediating the pathological effects of ApoE4 in vivo. Curr Alzheimer Res. 2014;11(6):549-57.

118. Gallo CM, Ho A, Beffert U. ApoER2: functional tuning through splicing. Front Mol Neurosci. 2020;13:144.

119. Wasser CR, Masiulis I, Durakoglugil MS, Lane-Donovan C, Xian X, Beffert U, et al. Differential splicing and glycosylation of Apoer2 alters synaptic plasticity and fear learning. Sci Signal. 2014;7(353):ra113.

120. Brown RH Jr. Amyotrophic lateral sclerosis. Insights from genetics. Arch Neurol. 1997:54(10):1246-50.

121. Bampton A, Gittings LM, Fratta P, Lashley T, Gatt A. The role of hnRNPs in frontotemporal dementia and amyotrophic lateral sclerosis. Acta Neuropathol. 2020;140(5):599-623.

122. Abramzon YA, Fratta P, Traynor BJ, Chia R. The overlapping genetics of amyotrophic lateral sclerosis and frontotemporal dementia. Front Neurosci. 2020;14:42.

123. Gendron TF, Petrucelli L. Disease mechanisms of C9ORF72 repeat expansions. Cold Spring Harb Perspect Med. 2018;8(4):a024224.

124. Yang Q, Jiao B, Shen L. The development of C9orf72-related amyotrophic lateral sclerosis and frontotemporal dementia disorders. Front Genet. 2020; 11:562758.

125. Barker HV, Niblock M, Lee YB, Shaw CE, Gallo JM. RNA misprocessing in C9orf72-linked neurodegeneration. Front Cell Neurosci. 2017;11:195.

126. Conlon EG, Lu L, Sharma A, Yamazaki T, Tang T, Shneider NA, et al. The C9ORF72 GGGGCC expansion forms RNA G-quadruplex inclusions and sequesters hnRNP H to disrupt splicing in ALS brains. Elife. 2016;5:e17820.

127. Deshaies JE, Shkreta L, Moszczynski AJ, Sidibé H, Semmler S, Fouillen A, et al. TDP-43 regulates the alternative splicing of hnRNP A1 to yield an aggregation-prone variant in amyotrophic lateral sclerosis. Brain. 2018; 141(5):1320-33.

128. Butti Z, Patten SA. RNA dysregulation in amyotrophic lateral sclerosis. Front Genet. 2018;9:712

129. Tripolszki K, Török D, Goudenège D, Farkas K, Sulák A, Török N, et al. Highthroughput sequencing revealed a novel SETX mutation in a Hungarian patient with amyotrophic lateral sclerosis. Brain Behav. 2017;7(4):e00669.

130. Maruyama $H$, Morino $H$, Ito $H$, Izumi $Y$, Kato $H$, Watanabe $Y$, et al. Mutations of optineurin in amyotrophic lateral sclerosis. Nature. 2010;465(7295):223-6.

131. Perrone B, La Cognata V, Sprovieri T, Ungaro C, Conforti FL, Andò S, et al. Alternative splicing of ALS genes: misregulation and potential therapies. Cell Mol Neurobiol. 2020;40(1):1-14.

132. Kolb SJ, Coffey CS, Yankey JW, Krosschell K, Arnold WD, Rutkove SB, et al. Natural history of infantile-onset spinal muscular atrophy. Ann Neurol. 2017; 82(6):883-91.

133. Prior TW, Krainer AR, Hua Y, Swoboda KJ, Snyder PC, Bridgeman SJ, et al. A positive modifier of spinal muscular atrophy in the SMN2 gene. Am J Hum Genet. 2009;85(3):408-13.

134. Slaugenhaupt SA, Gusella JF. Familial dysautonomia. Curr Opin Genet Dev. 2002;12(3):307-11.

135. Anderson SL, Coli R, Daly IW, Kichula EA, Rork MJ, Volpi SA, et al. Familial dysautonomia is caused by mutations of the IKAP gene. Am J Hum Genet. 2001;68(3):753-8.

136. He F, Jacobson A. Nonsense-mediated mRNA decay: degradation of defective transcripts is only part of the story. Annu Rev Genet. 2015;49:33966.

137. Dietrich P, Dragatsis I. Familial dysautonomia: mechanisms and models. Genet Mol Biol. 2016;39(4):497-514.

138. Paulson H. Repeat expansion diseases. Handb Clin Neurol. 2018;147:105-23.

139. Zhang N, Ashizawa T. RNA toxicity and foci formation in microsatellite expansion diseases. Curr Opin Genet Dev. 2017:44:17-29.

140. La Spada AR, Taylor JP. Repeat expansion disease: progress and puzzles in disease pathogenesis. Nat Rev Genet. 2010;11(4):247-58.

141. Gatchel JR, Zoghbi HY. Diseases of unstable repeat expansion: mechanisms and common principles. Nat Rev Genet. 2005;6(10):743-55.

142. Hale MA, Johnson NE, Berglund JA. Repeat-associated RNA structure and aberrant splicing. Biochim Biophys Acta Gene Regul Mech. 2019;1862(11-12): 194405. 
143. Romo L, Mohn ES, Aronin N. A fresh look at Huntingtin mRNA processing in Huntington's disease. J Huntingtons Dis. 2018;7(2):101-8.

144. Quemener AM, Bachelot L, Forestier A, Donnou-Fournet E, Gilot D, Galibert MD. The powerful world of antisense oligonucleotides: From bench to bedside. Wiley Interdiscip Rev RNA. 2020;11(5):e1594.

145. Disterer P, Kryczka A, Liu Y, Badi YE, Wong JJ, Owen JS, et al. Development of therapeutic splice-switching oligonucleotides. Hum Gene Ther. 2014; 25(7):587-98.

146. Brolin C, Lim EWK, Nielsen PE. In vivo administration of splice switching PNAs using the mdx mouse as a model system. Methods Mol Biol. 2020 2105:241-50.

147. Kole R, Krainer AR, Altman S. RNA therapeutics: beyond RNA interference and antisense oligonucleotides. Nat Rev Drug Discov. 2012;11(2):125-40.

148. Li D, Mastaglia FL, Fletcher S, Wilton SD. Precision medicine through antisense oligonucleotide-mediated exon skipping. Trends Pharmacol Sci. 2018;39(11):982-94.

149. Khvorova A, Watts JK. The chemical evolution of oligonucleotide therapies of clinical utility. Nat Biotechnol. 2017;35(3):238-48

150. Zamecnik PC, Stephenson ML. Inhibition of Rous sarcoma virus replication and cell transformation by a specific oligodeoxynucleotide. Proc Natl Acad Sci U S A. 1978:75(1):280-4.

151. Aung-Htut MT, Mclntosh CS, Ham KA, Pitout IL, Flynn LL, Greer K, et al. Systematic approach to developing splice modulating antisense oligonucleotides. Int J Mol Sci. 2019;20(20):5030.

152. Fletcher S, Honeyman K, Fall AM, Harding PL, Johnsen RD, Steinhaus JP, et al. Morpholino oligomer-mediated exon skipping averts the onset of dystrophic pathology in the mdx mouse. Mol Ther. 2007;15(9):1587-92.

153. McClorey G, Fall AM, Moulton HM, Iversen PL, Rasko JE, Ryan M, et al. Induced dystrophin exon skipping in human muscle explants. Neuromuscul Disord. 2006;16(9-10):583-90.

154. Harding PL, Fall AM, Honeyman K, Fletcher S, Wilton SD. The influence of antisense oligonucleotide length on dystrophin exon skipping. Mol Ther 2007;15(1):157-66

155. Mclntosh CS, Aung-Htut MT, Fletcher S, Wilton SD. Removal of the polyglutamine repeat of Ataxin-3 by redirecting pre-mRNA processing. Int J Mol Sci. 2019;20(21):5434.

156. Forsbach A, Nemorin JG, Montino C, Müller C, Samulowitz U, Vicari AP, et al. Identification of RNA sequence motifs stimulating sequence-specific TLR8dependent immune responses. J Immunol. 2008;180(6):3729-38.

157. Li D, Mastaglia FL, Fletcher S, Wilton SD. Progress in the molecular pathogenesis and nucleic acid therapeutics for Parkinson's disease in the precision medicine era. Med Res Rev. 2020;40(6):2650-81.

158. Aung-Htut MT, McIntosh CS, West KA, Fletcher S, Wilton SD. In vitro validation of phosphorodiamidate morpholino oligomers. Molecules. 2019;24(16):2922.

159. Summerton JE. Morpholino, siRNA, and S-DNA compared: impact of structure and mechanism of action on off-target effects and sequence specificity. Curr Top Med Chem. 2007:7(7):651-60.

160. Arora V, Devi GR, Iversen PL. Neutrally charged phosphorodiamidate morpholino antisense oligomers: uptake, efficacy and pharmacokinetics. Curr Pharm Biotechnol. 2004;5(5):431-9.

161. Summerton J, Weller D. Morpholino antisense oligomers: design, preparation, and properties. Antisense Nucleic Acid Drug Dev. 1997;7(3):187-95.

162. Aartsma-Rus A, Corey DR. The 10th oligonucleotide therapy approved: Golodirsen for duchenne muscular dystrophy. Nucleic Acid Ther. 2020;30(2):67-70.

163. Anwar S, Yokota T. Golodirsen for Duchenne muscular dystrophy. Drugs Today (Barc). 2020;56(8):491-504.

164. Alfano LN, Charleston JS, Connolly AM, Cripe L, Donoghue C, Dracker R, et al. Long-term treatment with eteplirsen in nonambulatory patients with Duchenne muscular dystrophy. Medicine (Baltimore). 2019;98(26):e15858.

165. Beggs AH, Hoffman EP, Snyder JR, Arahata K, Specht L, Shapiro F, et al. Exploring the molecular basis for variability among patients with Becker muscular dystrophy: dystrophin gene and protein studies. Am J Hum Genet. 1991;49(1):54-67.

166. Hua Y, Sahashi K, Hung G, Rigo F, Passini MA, Bennett CF, et al. Antisense correction of SMN2 splicing in the CNS rescues necrosis in a type III SMA mouse model. Genes Dev. 2010;24(15):1634-44.

167. Anna A, Monika G. Splicing mutations in human genetic disorders: examples, detection, and confirmation. J Appl Genet. 2018;59(3):253-68.

168. Finkel RS, Mercuri E, Darras BT, Connolly AM, Kuntz NL, Kirschner J, et al. Nusinersen versus sham control in infantile-onset spinal muscular atrophy. N Engl J Med. 2017;377(18):1723-32.
169. Masten MC, Mink JW, Augustine EF. Batten disease: an expert update on agents in preclinical and clinical trials. Expert Opin Investig Drugs. 2020;29(12):1317-22.

170. Aartsma-Rus A, Watts JK. The Munich meeting: medical maturation, more mechanisms, and milasen. Nucleic Acid Ther. 2019;29(6):302-4.

171. Korecka JA, Thomas R, Christensen DP, Hinrich AJ, Ferrari EJ, Levy SA, et al. Mitochondrial clearance and maturation of autophagosomes are compromised in LRRK2 G2019S familial Parkinson's disease patient fibroblasts. Hum Mol Genet. 2019;28(19):3232-43.

172. Korecka JA, Talbot S, Osborn TM, de Leeuw SM, Levy SA, Ferrari EJ, et al. Neurite collapse and altered ER Ca (2+) control in human Parkinson disease patient iPSC-derived neurons with LRRK2 G2019S mutation. Stem Cell Reports. 2019;12(1):29-41.

173. Korecka JA, Thomas R, Hinrich AJ, Moskites AM, Macbain ZK, Hallett PJ, et al. Splice-switching antisense oligonucleotides reduce LRRK2 kinase activity in human LRRK2 transgenic mice. Mol Ther Nucleic Acids. 2020;21:623-35.

174. Haylett W, Swart C, van der Westhuizen F, van Dyk H, van der Merwe L, van der Merwe $C$, et al. Altered mitochondrial respiration and other features of mitochondrial function in Parkin-mutant fibroblasts from Parkinson's disease patients. Parkinsons Dis. 2016;2016:1819209.

175. Asai $\mathrm{H}$, Hirano M, Kiriyama T, Ikeda M, Ueno S. Naturally- and experimentally-designed restorations of the Parkin gene deficit in autosomal recessive juvenile parkinsonism. Biochem Biophys Res Commun. 2010;391(1):800-5

176. Trempe JF, Sauvé V, Grenier K, Seirafi M, Tang MY, Ménade M, et al. Structure of parkin reveals mechanisms for ubiquitin ligase activation. Science. 2013:340(6139):1451-5.

177. Li D, Aung-Htut MT, Ham KA, Fletcher S, Wilton SD. A splice intervention therapy for autosomal recessive juvenile Parkinson's disease arising from Parkin mutations. Int J Mol Sci. 2020;21(19):7282.

178. Stevenson TJ, Murray HC, Turner C, Faull RLM, Dieriks BV, Curtis MA. asynuclein inclusions are abundant in non-neuronal cells in the anterior olfactory nucleus of the Parkinson's disease olfactory bulb. Sci Rep. 2020; 10(1):6682.

179. Gallardo G, Holtzman DM. Antibody therapeutics targeting A $\beta$ and Tau. Cold Spring Harb Perspect Med. 2017;7(10):a024331.

180. Chakravarthy M, Chen S, Dodd PR, Veedu RN. Nucleic acid-based theranostics for tackling Alzheimer's disease. Theranostics. 2017;7(16):3933-47.

181. Chang JL, Hinrich AJ, Roman B, Norrbom M, Rigo F, Marr RA, et al. Targeting amyloid- $\beta$ precursor protein, app, splicing with antisense oligonucleotides reduces toxic amyloid- $\beta$ production. Mol Ther. 2018;26(6):1539-51.

182. Chakravarthy M, Veedu RN. BACE1 inhibition using 2'-OMePS steric blocking antisense oligonucleotides. Genes (Basel). 2019;10(9):705.

183. Wu L, Zhao L. ApoE2 and Alzheimer's disease: time to take a closer look. Neural Regen Res. 2016;11(3):412-3.

184. Huynh TV, Liao F, Francis CM, Robinson GO, Serrano JR, Jiang H, et al. Agedependent effects of apoE reduction using antisense oligonucleotides in a model of $\beta$-amyloidosis. Neuron. 2017;96(5):1013-23.e4.

185. Hinrich AJ, Jodelka FM, Chang JL, Brutman D, Bruno AM, Briggs CA, et al. Therapeutic correction of ApoER2 splicing in Alzheimer's disease mice using antisense oligonucleotides. EMBO Mol Med. 2016;8(4):328-45.

186. Hayes L, Coyne A, Jafar-Nejad P, Rigo F, Rothstein J. Strand-specific antisense oligonucleotides for C9ORF72-ALS/FTD (S25.004). Neurology. 2018; 90(15 Supplement):S25.004

187. Zhu Q, Jiang J, Gendron TF, McAlonis-Downes M, Jiang L, Taylor A, et al. Reduced C9ORF72 function exacerbates gain of toxicity from ALS/FTDcausing repeat expansion in C9orf72. Nat Neurosci. 2020;23(5):615-24.

188. Poplawski SG, Garbett KA, McMahan RL, Kordasiewicz HB, Zhao H, Kennedy AJ, et al. An antisense oligonucleotide leads to suppressed transcription of Hdac2 and long-term memory enhancement. Mol Ther Nucleic Acids. 2020; 19:1399-412.

189. Rohilla KJ, Gagnon KT. RNA biology of disease-associated microsatellite repeat expansions. Acta Neuropathol Commun. 2017;5(1):63.

190. Toonen LJA, Rigo F, van Attikum H, van Roon-Mom WMC. Antisense oligonucleotide-mediated removal of the polyglutamine repeat in spinocerebellar ataxia type 3 mice. Mol Ther Nucleic Acids. 2017;8:232-42.

191. Mueller C, Berry JD, McKenna-Yasek DM, Gernoux G, Owegi MA, Pothier LM et al. SOD1 suppression with adeno-associated virus and microrna in familial ALS. N Engl J Med. 2020;383(2):151-8.

192. Wilton SD, Fletcher S, Flynn L, Akkari PA. Treatment for SOD1 associated disease. 2020. Publication Number: WO/2020/222182 